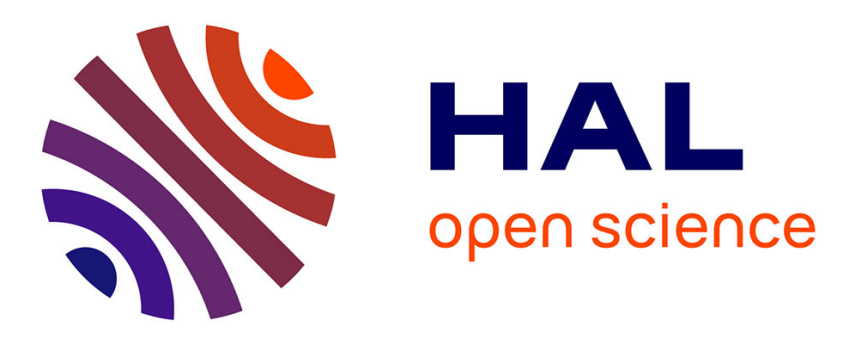

\title{
Wind comfort assessment by means of large eddy simulation with lattice Boltzmann method in full scale city area
}

\author{
Jérôme Jacob, Pierre Sagaut
}

\section{To cite this version:}

Jérôme Jacob, Pierre Sagaut. Wind comfort assessment by means of large eddy simulation with lattice Boltzmann method in full scale city area. Building and Environment, 2018, 139, pp.110 - 124. 10.1016/j.buildenv.2018.05.015 . hal-02114339

\section{HAL Id: hal-02114339 \\ https://hal.science/hal-02114339}

Submitted on 29 Apr 2019

HAL is a multi-disciplinary open access archive for the deposit and dissemination of scientific research documents, whether they are published or not. The documents may come from teaching and research institutions in France or abroad, or from public or private research centers.
L'archive ouverte pluridisciplinaire HAL, est destinée au dépôt et à la diffusion de documents scientifiques de niveau recherche, publiés ou non, émanant des établissements d'enseignement et de recherche français ou étrangers, des laboratoires publics ou privés. 


\title{
Wind comfort assessment by means of large eddy simulation with lattice Boltzmann method in full scale city area
}

\author{
J. Jacob*, P. Sagaut \\ Aix Marseille Univ, CNRS, Centrale Marseille, M2P2 UMR 7340, 13451 Marseille, France
}

\section{A R T I C L E I N F O}

\section{Keywords:}

Large-Eddy Simulation

Lattice Boltzmann method

Urban flow

Pedestrian wind comfort

\begin{abstract}
A B S T R A C T
Large-eddy simulations based on the Lattice-Boltzmann method of the flow in a realistic, full scale urban area are performed to compare several wind comfort criteria. It is observed that popular criteria for pedestrian comfort lead to very different conclusions, due to the access to high spatio-temporal resolution data. Different mixed strategies based on the combination of several criteria are proposed and compared to enhance pedestrian wind comfort assessment in practical cases.
\end{abstract}

\section{Introduction}

Pedestrian comfort is a global field of urban physics dealing with wind comfort, pollutant dispersion and thermal comfort close to the ground of cities. It can be addressed using either wind tunnel or in situ measurements that provide data at specific locations or using Computational Fluid Dynamics (CFD) which gives access to data over wide areas with very high spatial resolution. All these approaches are complementary considering that in situ and wind tunnel measurements permit to generate complete database that will be used to validate numerical model and to define guidelines for CFD studies which permit to obtain plenty of data on full scale geometries to assess pedestrian comfort.

Pedestrian wind comfort is sensitive to several kind of parameters such as the local wind (mean velocity, turbulent intensity), the location of the city (atmospheric conditions, building density) or the peoples (age, weight) so it is necessary to find or define universal rules to study it. In the literature those studies are mainly based on a mixing of meteorological data, aerodynamic data and comfort criterion to address local wind comfort in cities. Different criteria have been proposed in the literature, which are observed to a significant dispersion of results in some cases. Ratcliff and Peterka [1], Ohba et al. [2], Bottema [3] and Koss [4] listed and compared several wind comfort criteria such as those discussed in Davenport [5], Gandemer [6,7], Isyumov and Davenport [8,9], Lawson and Penwarden [10], Melbourne [11] and Hunt et al. [12]. This variability of pedestrian comfort criteria is significantly impacted by the nature of their input data: time-averaged velocity, turbulent intensity and averaging period length, from a few seconds to a few hours. In order to reduce the uncertainty induced by this high sensitivity of wind comfort criteria, comparing them on the same case can be a good way to evaluate pedestrian comfort quality but many kind of aerodynamic data can be necessary to this end. CFD is then an interesting tool since it permits to assess different data at many locations with a moderate effort.

The use of CFD for urban flow simulation is more and more widespread. Many studies are available in the literature and best practice guidelines [13-15] on the use of CFD for that kind of application have been proposed. Most of existing CFD simulations have been performed using the Reynolds Average Navier Stokes (RANS) approach, which resolves only the mean, time-averaged flow while the turbulent motion is modelled, on simplified [16-19] or realistic [18,20-29] geometries. However time-resolved approaches such as Detached Eddy Simulation (DES, see Ref. [30]) have been used recently on both simplified isolated buildings geometries [31,32] and complex urban area like Shinjuku AIJ test case [32]. Steady RANS simulations are widely used because of their low computational cost, but they do not permit to assess unsteady data, and therefore do not allow to consider all existing wind comfort criteria. Another commonly reported weakness is that they over-predict the turbulent energy dissipation, leading to a bad prediction of recirculation bubbles observed at the top or in the wake of buildings. To cure that problem Large Eddy Simulation (LES, see Refs. [33,34]) which allows for the direct resolution of a wide range of turbulent frequencies, can be used. However, the computational cost increase associated to LES due to its high spatio-temporal resolution can become a problem when simulations of flow over complex realistic geometries is targeted. These methods were first applied to simplified geometries or reduced area of cities, e.g. Refs. [35-39], but also for simulations of pollutant dispersion over complex urban areas [40], wind loads on buildings [41]

\footnotetext{
* Corresponding author.

E-mail address: jerome.jacob@univ-amu.fr (J. Jacob).
} 
Table 1

Example of existing CFD simulations at pedestrian level.

\begin{tabular}{|c|c|c|c|c|c|c|}
\hline & Turbulence model & Computational domain & Area of interest & Pedestrian level & Wind comfort criteria & Grid points \\
\hline $\mathrm{He}$ [35] & LES & $700 \times 700 m^{2}$ & & $1.7 m$ & & \\
\hline Blocken [20] & RANS & $900 \times 700 m^{2}$ & & $1.75 m$ & Bottema [3] & $2.9 \times 10^{6}$ \\
\hline Blocken [21] & RANS & $3000 \times 3000 \mathrm{~m}^{2}$ & Amsterdam Arena & $2 m$ & NEN8100 [45] & $2.8 \times 10^{6}$ \\
\hline Letzel [42] & LES & $1.6 \mathrm{~km}^{2}$ & $\simeq 1 \mathrm{~km}^{2}$ & $2.5 m$ & & $7.2 \times 10^{8} \& 1.6 \times 10^{9}$ \\
\hline Jansen [23] & RANS & $2077 \times 1838 m^{2}$ & $1918 \times 1430 m^{2}$ & $1.75 m$ & $\begin{array}{l}\text { NEN8100 [45], } \\
\text { Isyumov [8], } \\
\text { Melbourne [11], } \\
\text { Lawson [46] }\end{array}$ & $7.5 \times 10^{6}$ \\
\hline Montazeri [26] & RANS & $2076 \times 1963 m^{2}$ & $\begin{array}{l}\text { Antwerp tower } \\
\text { balconies }\end{array}$ & $1.7 m$ & NEN8100 [45] & $\simeq 16 \times 10^{6}$ \\
\hline Blocken [22] & RANS & $\simeq 2700 \times 2300 \mathrm{~m}^{2}$ & $1600 \times 1100 \mathrm{~m}^{2}$ & $1.75 m$ & NEN8100 [45] & $7.5 \times 10^{6}$ \\
\hline Shi [47] & RANS & $3000 \times 3000 \mathrm{~m}^{2}$ & & $1.5 m$ & & $1.14 \times 10^{6}$ \\
\hline Zheng [29] & RANS & $7950 \times 7650 \mathrm{~m}^{2}$ & $\begin{array}{l}\text { Outdoor platforms of } \\
\text { megatall building }\end{array}$ & $2 m$ & $\begin{array}{l}\text { NEN8100 [45], } \\
\text { Lawson [46] }\end{array}$ & $7.18 \times 10^{6}$ \\
\hline Kang [24] & RANS & $1000 \times 1000 m^{2}$ & & $1.75 m$ & Isyumov [8] & $\simeq 14.2 \times 10^{6}$ \\
\hline Adamek [43] & LES & $4270 \times 2440 \mathrm{~m}^{2}$ & $\simeq 600 \times 600 \mathrm{~m}^{2}$ & $1.5 m$ & Soligo [48] & $1.1 \times 10^{6}$ \\
\hline Present study & LES & $4600 \times 5000 m^{2}$ & Shinjuku area & $2 m$ & & $22 \times 10^{6}-136 \times 10^{6}$ \\
\hline
\end{tabular}

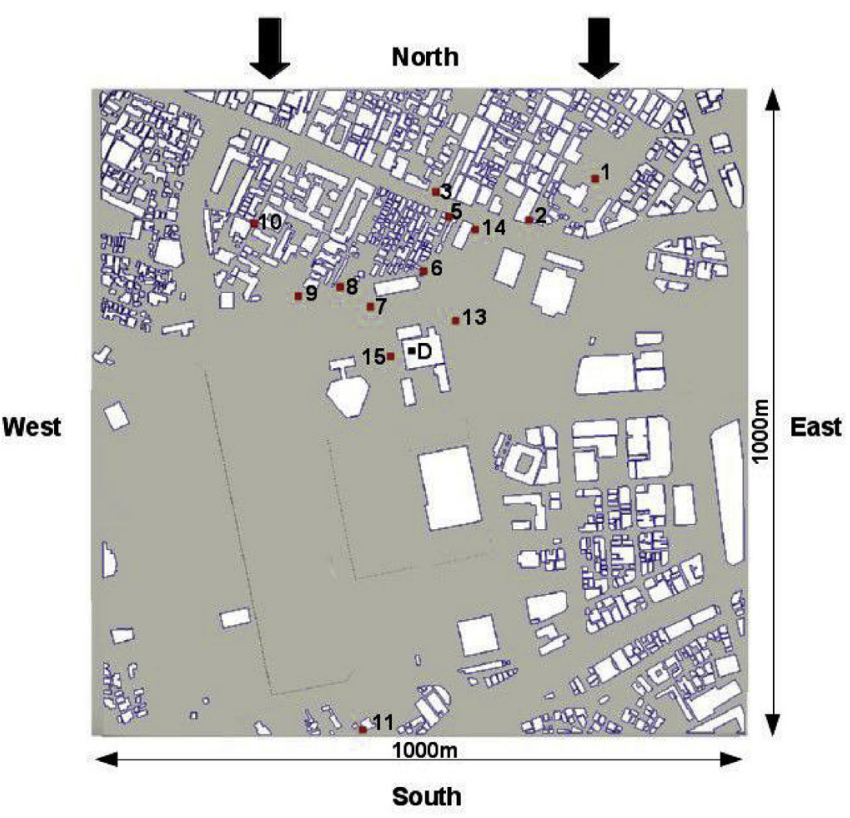

Fig. 1. Positions of measurements points.

and pedestrian wind comfort assessment [42,43]. A review of urban CFD simulations at pedestrian level is given in Table 1. In order to reduce computational cost of LES simulation it is possible to switch from the classical CFD approach base on the Navier-Stokes equations to Lattice Boltzmann method (LBM) solvers which are very efficient for parallel computations of separated low Mach number flows. This is illustrated in Ahmad et al. [44], who performed simulations to assess pedestrian level gust index in a $19.2 \mathrm{~km} \times 4.8 \mathrm{~km} \times 1.0 \mathrm{~km}$ area of Tokyo with a $2 m$ finest grid resolution taking advantage of high efficiency of lattice Boltzmann method for parallel simulation. The LBM method is very interesting for CFD because it is fully local which avoid the use of complex and time consuming numerical methods and the complete algorithm needs only to access the data of the first order neighbors which increase the performance for parallel simulations. Furthermore the computational grid is based on a hierarchy of embedded uniform meshes with a ratio of 2 for the grid step between two successive refinement levels. The use of immersed boundary conditions allows to handle complex geometries such as city in a very easy and automatic way. This is also interesting considering that the ratio $d x / d t$ is kept identical at all grid refinement levels, which means that only the nodes at the finest refinement level are computed every time step reducing the number of floating point operations during the simulation.

The present study deals with the application of an LES-LBM solver to wind comfort assessment at pedestrian level in full scale urban geometry using different wind comfort criteria. The aim is to compare different existing criteria thanks to the high space-time resolution data provided by LES in a realistic configuration, and to check their coherency and robustness with respect to the accuracy of input data. In Section 2 key features of the Lattice Boltzmann method used in this paper are presented. Section 3 presents the validation of the present method on a realistic urban configuration, namely the case $\mathrm{F}$ of the Architectural Institute of Japan open database [14,27]. Section 4 is devoted to the results obtained dealing with pedestrian wind comfort assessment at a height of $2 \mathrm{~m}$ from the ground. Conclusions are given in Section 5 .

\section{Numerical method}

All the CFD simulations presented here have been carried out using a research version of ProLB [49] that use the Lattice Boltzmann Method [50-54] to solve fluid dynamics equations. It is based on the resolution of Boltzmann equation (Eq. (1)) that describes the evolution of a particle distribution function $f=f(\vec{x}, \vec{c}, t)$ which is related to the probability density of particles with velocity $\vec{c}$ at time t and position $\vec{x}$. This equation is solved on a $\mathrm{D} d \mathrm{Q} q$ ( $d$ dimensions, $q$ discrete velocities) lattice.

Table 2

Grid parameters and computational time for the Shinjuku area test case.

\begin{tabular}{|c|c|c|c|c|c|c|}
\hline Grid & $\Delta x_{\min }(\mathrm{m})$ & $\Delta t_{\min }(\mathrm{s})$ & Grid refinement level & Grid points $\left(10^{6}\right)$ & Number of processors & Computational time for $1 \mathrm{~h}$ \\
\hline Coarse & 2 & 0.03 & 5 & 22 & 120 & $9 \mathrm{~h}$ \\
\hline Basic & 1 & 0.015 & 6 & 54 & 240 & $20 \mathrm{~h}$ \\
\hline Fine & 0.5 & 0.0075 & 7 & 136 & 504 & $50 \mathrm{~h}$ \\
\hline
\end{tabular}




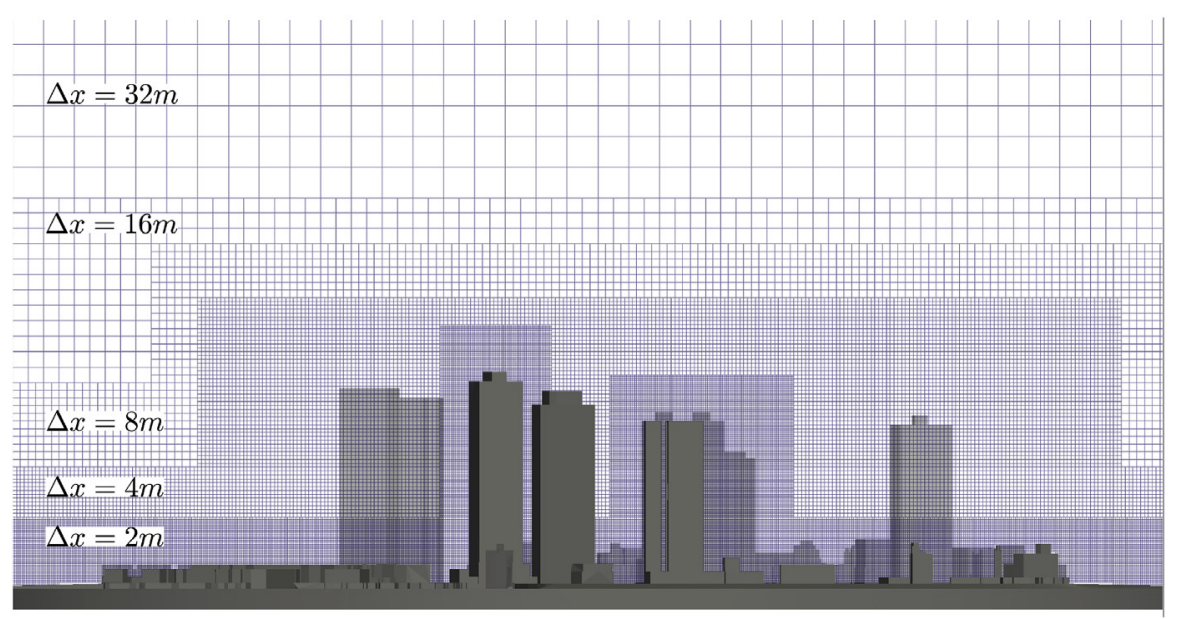

Fig. 2. Grid visualization for the coarse case.

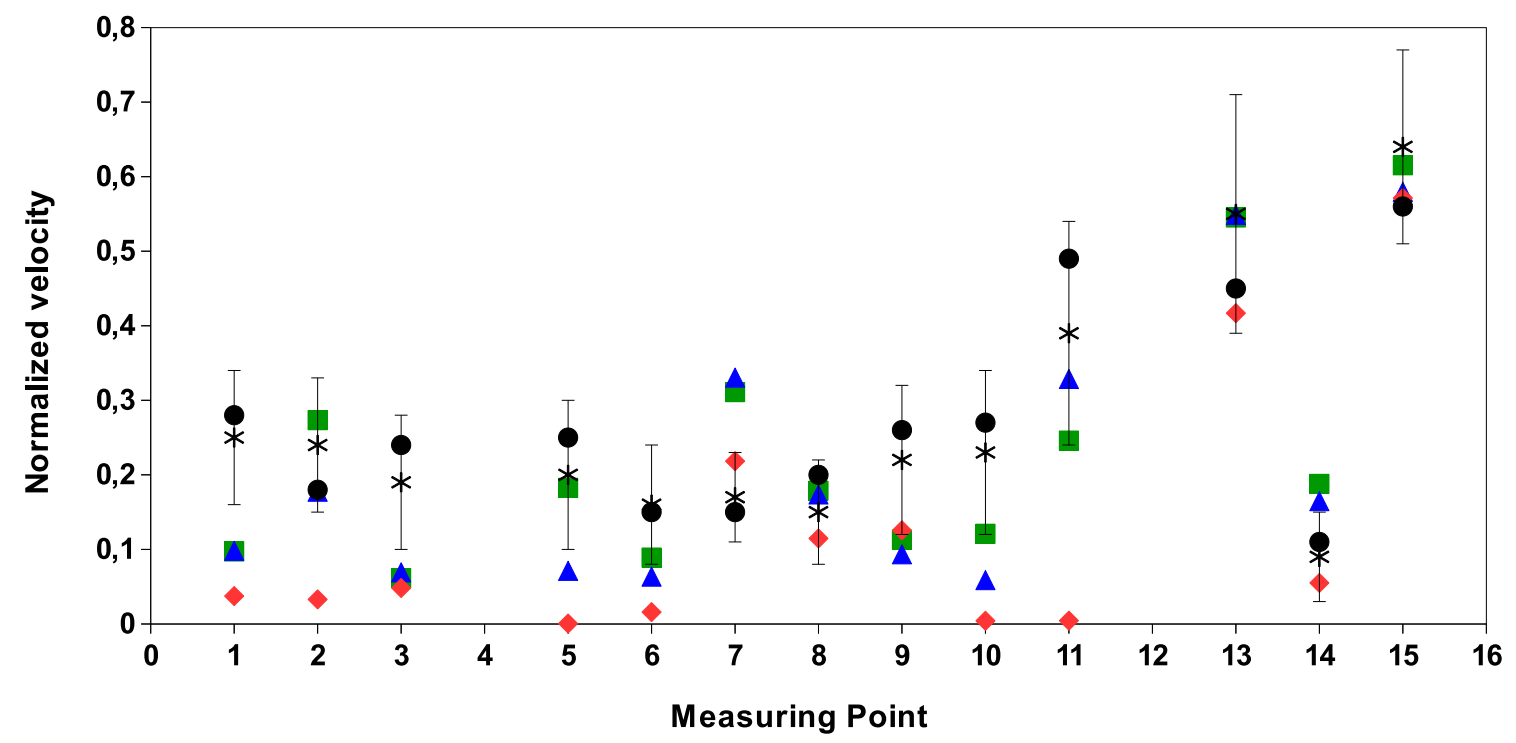

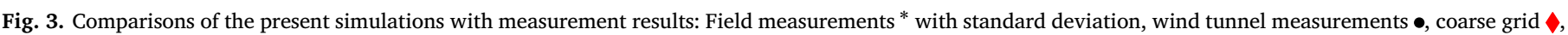
basic grid $\boldsymbol{\Delta}$ and fine grid $\square$.
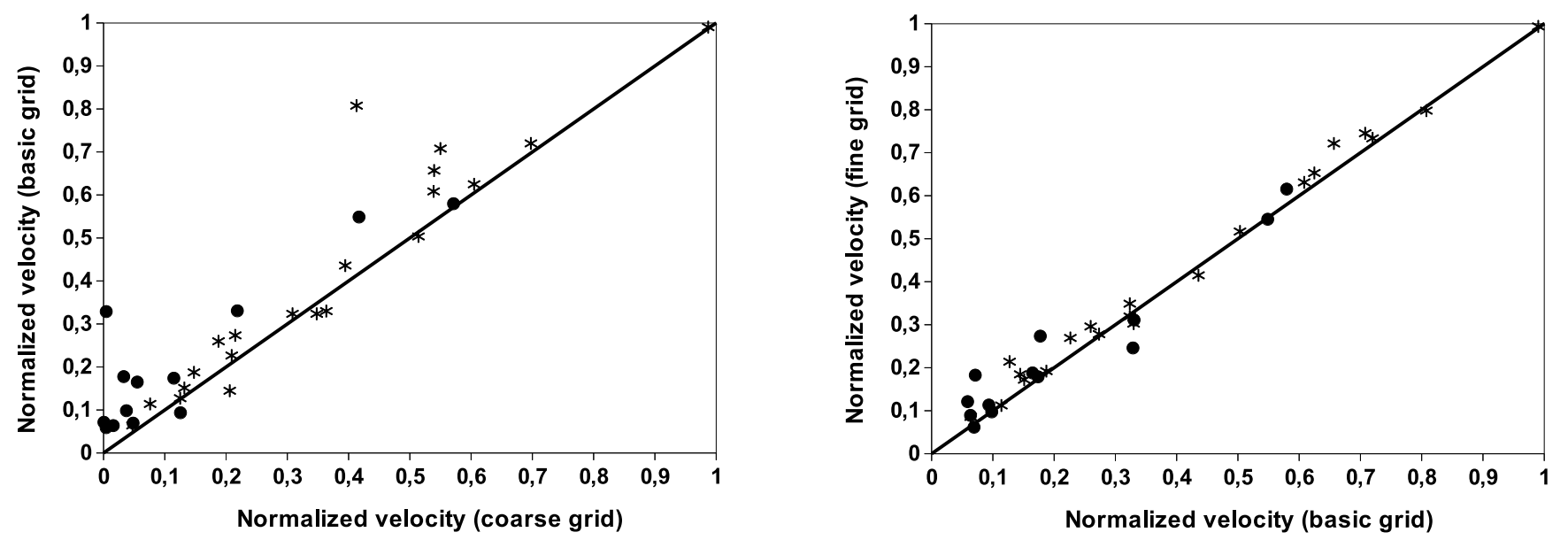

Fig. 4. Grid sensitivity analysis, • represent values on previous measurement points and * represent values on other points in the domain. 


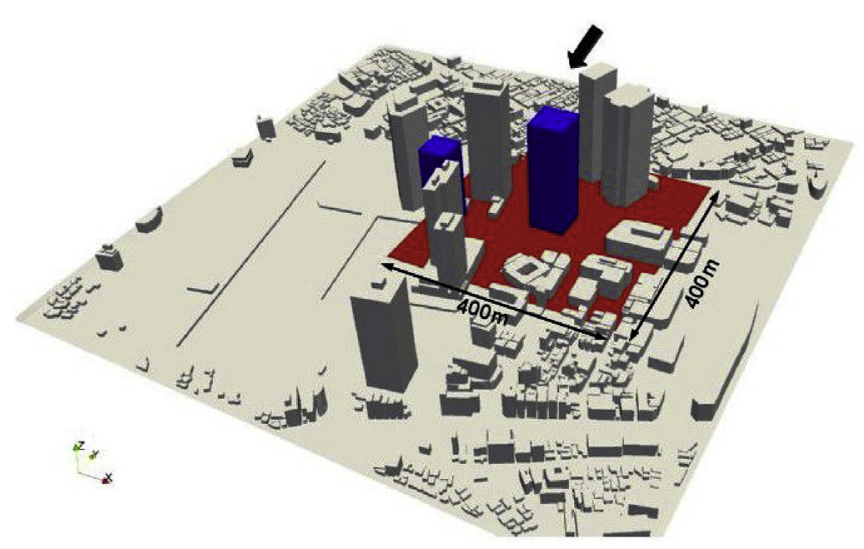

Fig. 5. Shinjuku area with new buildings (blue) and the area of interest (red), the arrow indicates the inflow direction. (For interpretation of the references to colour in this figure legend, the reader is referred to the Web version of this article.)

Table 3

Different criteria for wind effect on human activities.

\begin{tabular}{lll}
\hline Hunt [12] & $U_{e}=\bar{U}+3 \sigma_{U}$ & \\
& $U_{e}<6 \mathrm{~m} / \mathrm{s}$ & Comfort situation for all activities \\
& $U_{e}<9 \mathrm{~m} / \mathrm{s}$ & Most performance unaffected \\
& $U_{e}<15 \mathrm{~m} / \mathrm{s}$ & Good control of walking \\
& $U_{e}<20 \mathrm{~m} / \mathrm{s}$ & Good safety of walking \\
& $U_{e}=\overline{U_{3 s}}$ & \\
& $U_{e}<5 \mathrm{~m} / \mathrm{s}$ & No effect on people \\
& $5 \mathrm{~m} / \mathrm{s}<U_{e}<10 \mathrm{~m} / \mathrm{s}$ & Some effects on people \\
& $10 \mathrm{~m} / \mathrm{s}<U_{e}<15 \mathrm{~m} / \mathrm{s}$ & Serious effects on people \\
& $U_{e}>15 \mathrm{~m} / \mathrm{s}$ & Very serious effects on people \\
\hline
\end{tabular}

Table 4

Different wind comfort criteria.

\begin{tabular}{lllll}
\hline Class & Criteria & $U_{e}$ & $U_{T H R}$ & $P_{\max }$ \\
\hline \multirow{2}{*}{ A (Sitting) } & NEN 8100 [45] & $\overline{U_{1 H}}$ & $5 \mathrm{~m} / \mathrm{s}$ & $2.5 \%$ \\
& Lawson [46] & $\overline{U_{1 H}}$ & $3.35 \mathrm{~m} / \mathrm{s}$ & $2 \%$ \\
& & $\overline{U_{3 s}}$ & $5.7 \mathrm{~m} / \mathrm{s}$ & $2 \%$ \\
& Melbourne [11] & $\overline{U_{1 H}}+3.5 \sigma_{U}$ & $10 \mathrm{~m} / \mathrm{s}$ & $0.022 \%$ \\
& Isyumov [8] & $\overline{U_{1 H}}$ & $5.45 \mathrm{~m} / \mathrm{s}$ & $1.5 \%$ \\
& Soligo [48] & $\overline{U_{1 H}}$ & $2.5 \mathrm{~m} / \mathrm{s}$ & $20 \%$ \\
\hline \multirow{2}{*}{ B (Standing) } & NEN 8100 [45] & $\overline{U_{1 H}}$ & $5 \mathrm{~m} / \mathrm{s}$ & $5 \%$ \\
& Lawson [46] & $\overline{U_{1 H}}$ & $5.45 \mathrm{~m} / \mathrm{s}$ & $2 \%$ \\
& & $\overline{U_{3 s}}$ & $9.3 \mathrm{~m} / \mathrm{s}$ & $2 \%$ \\
& Melbourne [11] & $\overline{U_{1 H}}+3.5 \sigma_{U}$ & $13 \mathrm{~m} / \mathrm{s}$ & $0.022 \%$ \\
& Isyumov [8] & $\overline{U_{1 H}}$ & $7.95 \mathrm{~m} / \mathrm{s}$ & $1.5 \%$ \\
& Soligo [48] & $\overline{U_{1 H}}$ & $3.9 \mathrm{~m} / \mathrm{s}$ & $20 \%$ \\
\hline \multirow{2}{*}{ C (Walking) } & NEN 8100 [45] & $\overline{U_{1 H}}$ & $5 \mathrm{~m} / \mathrm{s}$ & $10 \%$ \\
& Lawson [46] & $\overline{U_{1 H}}$ & $7.95 \mathrm{~m} / \mathrm{s}$ & $2 \%$ \\
& & $\overline{U_{3 s}}$ & $13.6 \mathrm{~m} / \mathrm{s}$ & $2 \%$ \\
& Melbourne [11] & $\overline{U_{1 H}}+3.5 \sigma_{U}$ & $16 \mathrm{~m} / \mathrm{s}$ & $0.022 \%$ \\
& Isyumov [8] & $\overline{U_{1 H}}$ & $10.75 \mathrm{~m} / \mathrm{s}$ & $1.5 \%$ \\
& Soligo [48] & $\overline{U_{1 H}}$ & $5 \mathrm{~m} / \mathrm{s}$ & $20 \%$ \\
\hline
\end{tabular}

$\frac{\partial f}{\partial t}+\vec{c} \cdot \vec{\nabla} f=\Omega(f)$

The lattice Boltzmann equation (Eq. (2)) with time step $\Delta t$ and space step $\overrightarrow{\Delta x}=\overrightarrow{c_{\alpha}} \Delta t$ is given by Ref. [55].

$f_{\alpha}\left(\vec{x}+\overrightarrow{c_{\alpha}} \Delta t, t+\Delta t\right)-f_{\alpha}(\vec{x}, t)=\Omega_{\alpha}(\vec{x}, t)$

with $f_{\alpha}$ the distribution function following the $\alpha$ direction and $\Omega_{\alpha}$ the collision operator. In this work the lattice use is the D3Q19 lattice given

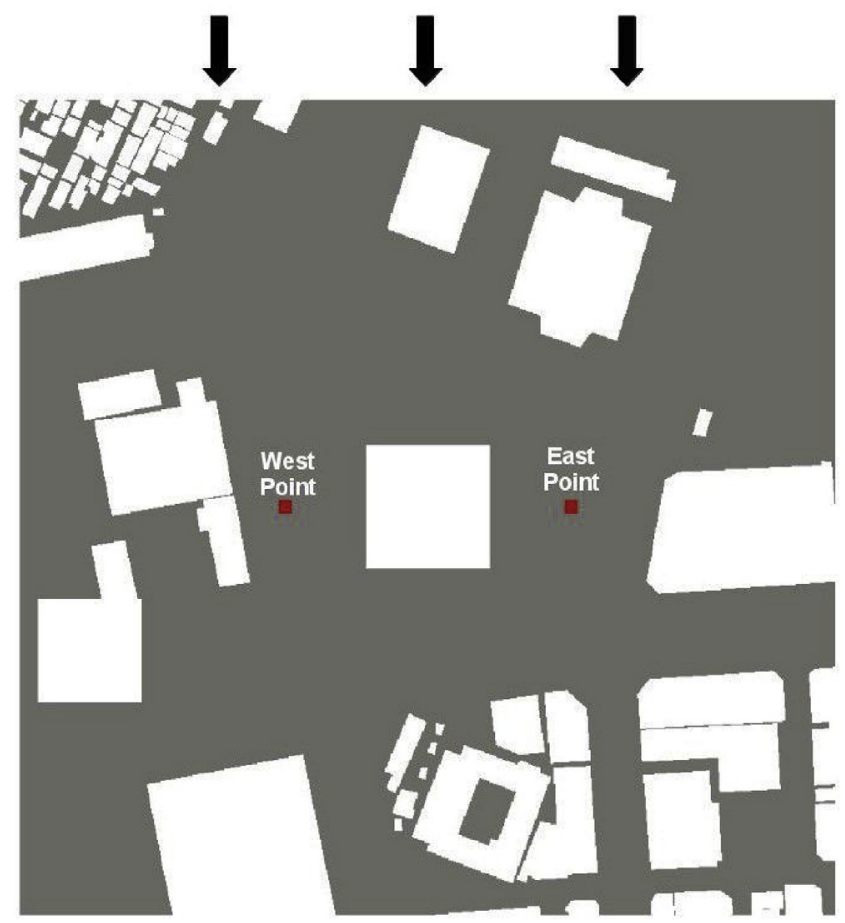

Fig. 6. Localization of the East and West points.

by,

$$
\vec{c}_{\alpha}= \begin{cases}(0,0,0) & \alpha=0 \\ ( \pm 1,0,0),(0, \pm 1,0),(0,0, \pm 1) & \alpha=1-6 \\ ( \pm 1, \pm 1,0),( \pm 1,0, \pm 1),(0, \pm 1, \pm 1) & \alpha=7-18\end{cases}
$$

The solution of Eq. (2) is usually computed in two steps using a Strang-type splitting. First the collision step $f_{\alpha}^{\text {coll }}(\vec{x}, t)=f_{\alpha}(\vec{x}, t)+\Omega_{\alpha}(\vec{x}, t)$ is performed, followed by the propagation step $f_{\alpha}\left(\vec{x}+\overrightarrow{c_{\alpha}} \Delta t, t+\Delta t\right)=f_{\alpha}^{\text {coll }}(\vec{x}, t)$. The macroscopic quantities (density $\rho$, momentum $\rho u_{i}$ and momentum flux tensor $\Pi_{i j}$ ) are then reconstructed computing the moments of the distribution functions, i.e.

$\rho=\sum_{\alpha=0}^{q-1} f_{\alpha}$

$\rho u_{i}=\sum_{\alpha=0}^{q-1} f_{\alpha} c_{\alpha i}$

$\Pi_{i j}=\sum_{\alpha=0}^{q-1} f_{\alpha} c_{\alpha i} c_{\alpha j}$

The collision operator, which is interpreted as a relaxation towards an equilibrium state, may involve either a single relaxation time (BGK collision) [54] or several ones, leading to a multiple relaxation time (MRT) method [56]. MRT models are expected to be numerically more stable than BGK models, because they allow for a finer tuning of the effective viscosity. Nevertheless, different methods such as collision kernel regularization [57] allow to increase the BGK model stability with a very small extra computational cost. Such a regularized collision operator with a single relaxation time expressed in Eq. (5) is used in the present work,

$\Omega_{\alpha}=-\frac{1}{\tau}\left(f_{\alpha}-f_{\alpha}^{e q}\right)=-\frac{1}{\tau} f_{\alpha}^{n e q}$

where $\tau=0.5+3 \nu$ is the dimensionless relaxation time, $\nu$ is the kinematic viscosity, $f_{\alpha}^{\text {neq }}$ is the non equilibrium distribution function and $f_{\alpha}^{e q}$ is the local equilibrium distribution function given by 


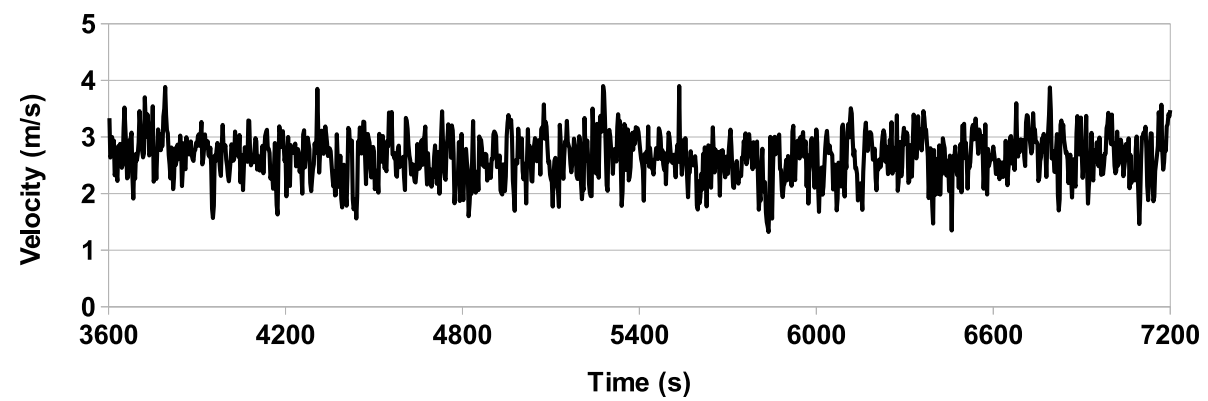

Fig. 7. Visualization of the velocity fluctuations on the West point in the case $U_{r e f}=1.69 \mathrm{~m} / \mathrm{s}$.

$f_{\alpha}^{e q}=\rho \omega_{\alpha}\left[1+\frac{c_{\alpha i} u_{i}}{c_{s}^{2}}+\frac{1}{2 c_{s}^{4}} Q_{\alpha i j} u_{i} u_{j}\right]$

with $c_{s}$ the speed of sound, $\omega_{\alpha}$ the weighting coefficients of the lattice and $Q_{\alpha i j}=c_{\alpha i} c_{\alpha j}-c_{s}^{2} \delta_{i j}$. Following the Chapman-Enskog expansion the non equilibrium function can be approximated by Refs. [57,58].

$f_{\alpha}^{n e q} \approx-\frac{\tau \omega_{\alpha}}{2 c_{s}^{2}} Q_{\alpha i j}\left(\frac{\partial \rho u_{j}}{\partial x_{i}}+\frac{\partial \rho u_{i}}{\partial x_{j}}\right)=\frac{Q_{\alpha i j}}{2 c_{s}^{4}} \sum_{\alpha} c_{\alpha i} c_{\alpha j}\left(f_{\alpha}-f_{\alpha}^{e q}\right)$

It is seen from Eq. (7) that the non equilibrium function can be computed using either the macroscopic quantities and their space derivatives or the local distribution functions. In the following, it is chosen to denote $f_{\alpha}^{\text {neq,FD }}$ the non equilibrium function computed using finite differences and $f_{\alpha}^{n e q, L B M}$ the non-equilibrium function computed from the local distribution functions, respectively. Using only $f_{\alpha}^{\text {neq,LBM }}$ can lead to numerical instability whereas considering only $f_{\alpha}^{\text {neq,FD }}$ can lead to strong numerical dissipation. To avoid these problems a mixed reconstruction is defined as

$f_{\alpha}^{n e q}=\sigma f_{\alpha}^{n e q, L B M}+(1-\sigma) f_{\alpha}^{n e q, F D}$

with $\sigma \in[0,1]$ and,

$f_{\alpha}^{n e q, L B}=\frac{Q_{\alpha i j}}{2 c_{s}^{4}} \sum_{\alpha} c_{\alpha i} c_{\alpha j}\left(f_{\alpha}-f_{\alpha}^{e q}\right)$

$f_{\alpha}^{n e q, F D}=-\frac{\tau \omega_{\alpha}}{2 c_{s}^{2}} Q_{\alpha i j}\left(\frac{\partial \rho u_{j}}{\partial x_{i}}+\frac{\partial \rho u_{i}}{\partial x_{j}}\right)$

The regularized collision operator used in this paper is obtained combining Eq. (5) and Eq. (8), yielding

$\Omega_{\alpha}=-\frac{1}{\tau}\left[\sigma f_{\alpha}^{n e q, L B M}+(1-\sigma) f_{\alpha}^{n e q, F D}\right]$

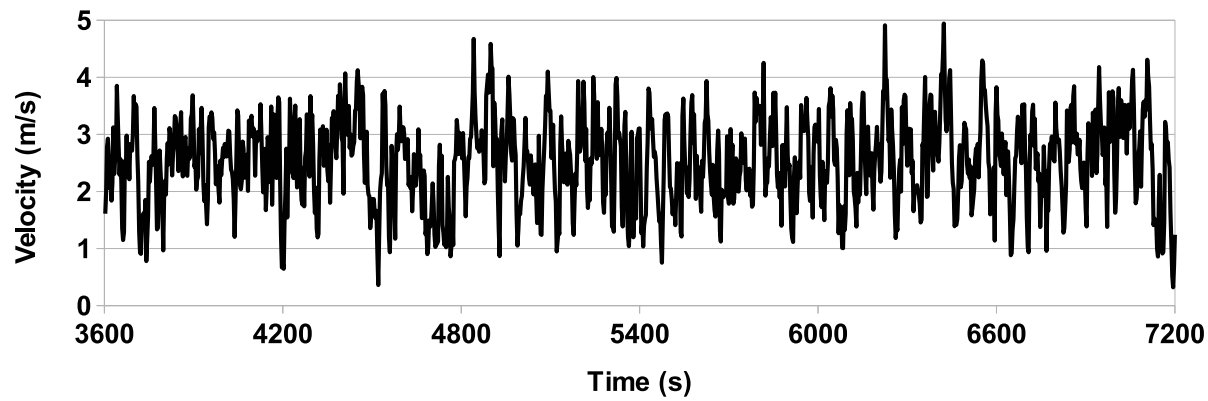

Fig. 8. Visualization of the velocity fluctuations on the East point in the case $U_{r e f}=1.69 \mathrm{~m} / \mathrm{s}$.

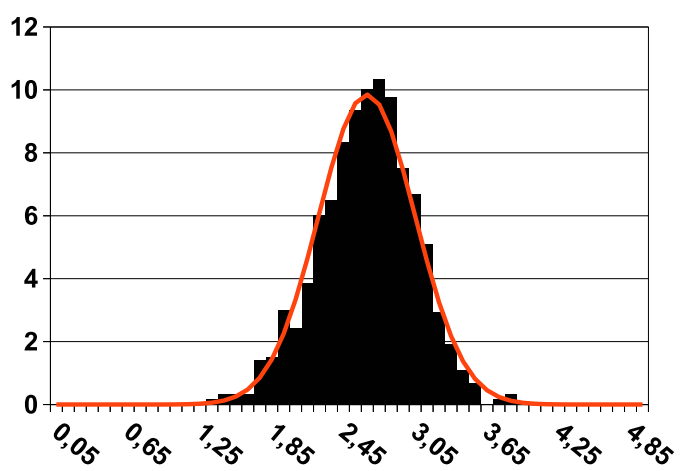

a)

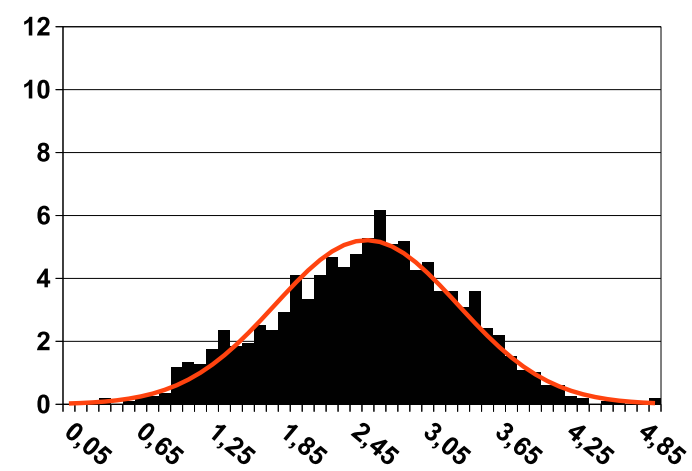

b)

Fig. 9. Velocity histograms (in black) and associate Gaussian distributions (in red) at a) West point and b) East point in the case $U_{\text {ref }}=1.69 \mathrm{~m} / \mathrm{s}$. (For interpretation of the references to colour in this figure legend, the reader is referred to the Web version of this article.) 


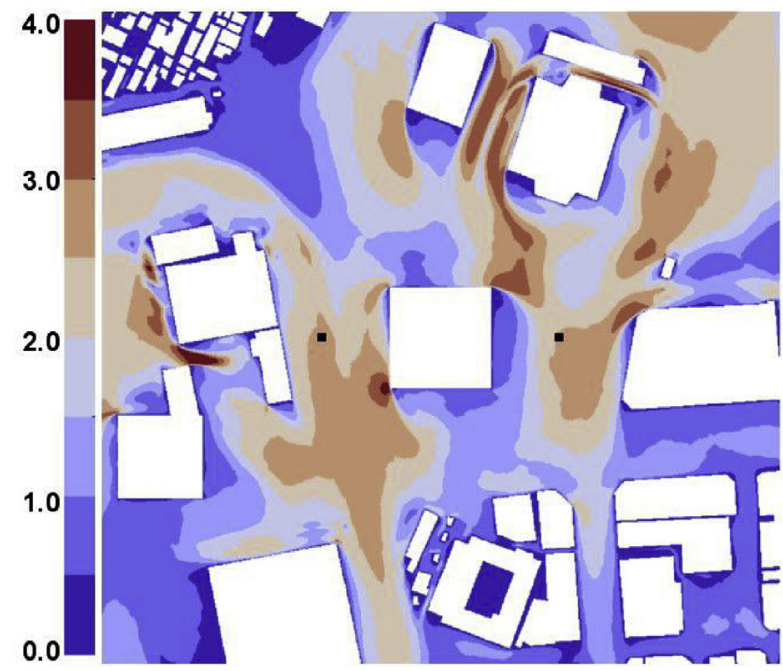

a) $\bar{U}(\mathrm{~m} / \mathrm{s})$

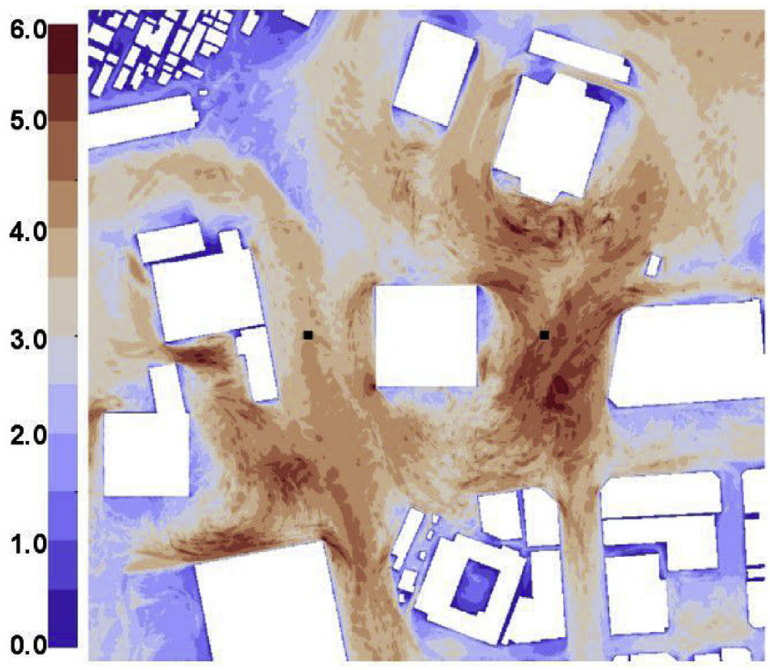

b) $\overline{U_{\max }^{3 s}}(\mathrm{~m} / \mathrm{s})$

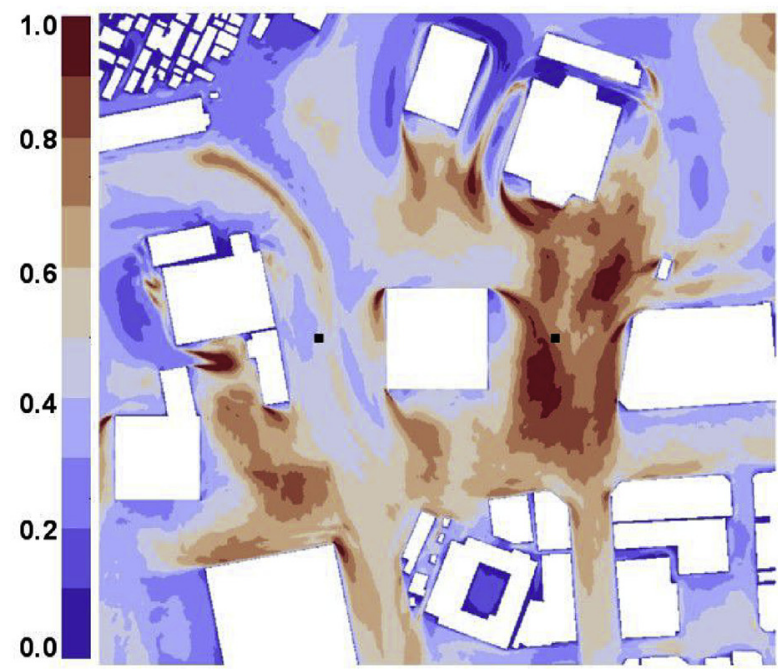

c) $\sigma_{U}(\mathrm{~m} / \mathrm{s})$
Fig. 10. Visualization of a) $1 \mathrm{~h}$ averaged velocity, b) $3 \mathrm{~s}$ averaged velocity and c) $1 \mathrm{~h}$ standard deviation of the velocity computed with $U_{\text {ref }}=1.69 \mathrm{~m} / \mathrm{s}$. The black points indicate the position of previous east and west points.

with $\sigma=0.97$, which is observed to be well suited for Implicit LargeEddy Simulation. Therefore, no explicit subgrid model is added for the simulations presented hereafter.

\section{Validation of the method}

\subsection{Description of the test case}

The present lattice Boltzmann model is first validated with simulations of the Shinjuku area in Tokyo corresponding to the case F of the AIJ open source database [14,27] for the north wind condition. This area is a $1 \mathrm{~km}^{2}$ part of Tokyo with both tall (up to $225 \mathrm{~m}$ height) and small buildings. Velocity measurements (Fig. 1) are available for that case at several locations, including both field measurements carried out from December 1975 to November 1983 at the beginning of the development of that area and wind tunnel measurements carried out based on the 1977 field measurements conditions. These data are available online (https://www.aij.or.jp/jpn/publish/cfdguide/index_e. htm) or can be found in Refs. [18,27].

It must be noticed here that no CAD data of the 1977 Shinjuku area were available so it was made thanks to photographs and old drawings as mentioned by Yoshie et al. [18] and Tominaga et al. [27]. Therefore differences can exist between the real urban area at the field measurement time and the geometry used for the CFD computations.

\subsection{Computational settings}

As the Shinjuku area is about $1 \mathrm{~km} \times 1 \mathrm{~km}$ with a height of $H=225$ meters for the highest building (Shinjuku Mitsui Building, point D in Fig. 1) a computational domain of $4600 \mathrm{~m} \times 5000 \mathrm{~m} \times 1500 \mathrm{~m}$ was designed. This domain ensures an upstream length of $4.5 \mathrm{H}$, a downstream length of $13 \mathrm{H}$ and a height of $6.5 \mathrm{H}$ with lateral boundaries placed $8 \mathrm{H}$ from the Shinjuku area in agreement with Franke et al. [13] and Tominaga et al. [14] best practice guidelines. As explained in Section 1 the computational grid is composed of several embedded volumes with uniform mesh. The computations were performed considering 3 different finest grid resolutions summarized in Table 2. A view of the coarsest mesh is shown in Fig. 2. The coarse grid is composed of several layers of refinement levels close to the ground, $\Delta x=2 \mathrm{~m}$ up to $70 \mathrm{~m}$ high (35 grid points) then $\Delta x$ is increased (by a ratio of 2) by layers of 12 points up to the maximal value $\Delta x=32 \mathrm{~m}$. The areas around the tall buildings were refined ( $\Delta x=2 m$ close to buildings) using individual refinement volumes to ensure that the different wakes will be correctly captured. Additional refinement levels were added around tall buildings, one volume $(\Delta x=4 m)$ including the different individual areas and another one $(\Delta x=8 m)$ surrounding the previously defined volume. The basic grid is based on the coarse one with an additional layer up to $40 \mathrm{~m}$ from the ground with $\Delta x=1 \mathrm{~m}$ and the same procedure was applied from basic to fine grid with a layer of $20 \mathrm{~m}(\Delta x=0.5 \mathrm{~m})$ from the ground. For all the 3 tested grids the measurements points of Fig. 1 are located in the finest resolution level.

At the inflow, the mean velocity profile is reconstructed from the values given in the AIJ data base, leading to $U(z)=0.895 z^{0.276}$. The lateral and top boundary conditions were defined as frictionless walls following the best practice guidelines [13,14] and a constant static pressure condition was prescribed at the outlet. Standard wall law [59] was used for the floor and the different buildings walls.

\subsection{Comparison with literature results}

For all of the 3 designed grid $1 \mathrm{~h}$ of physical time was simulated to 


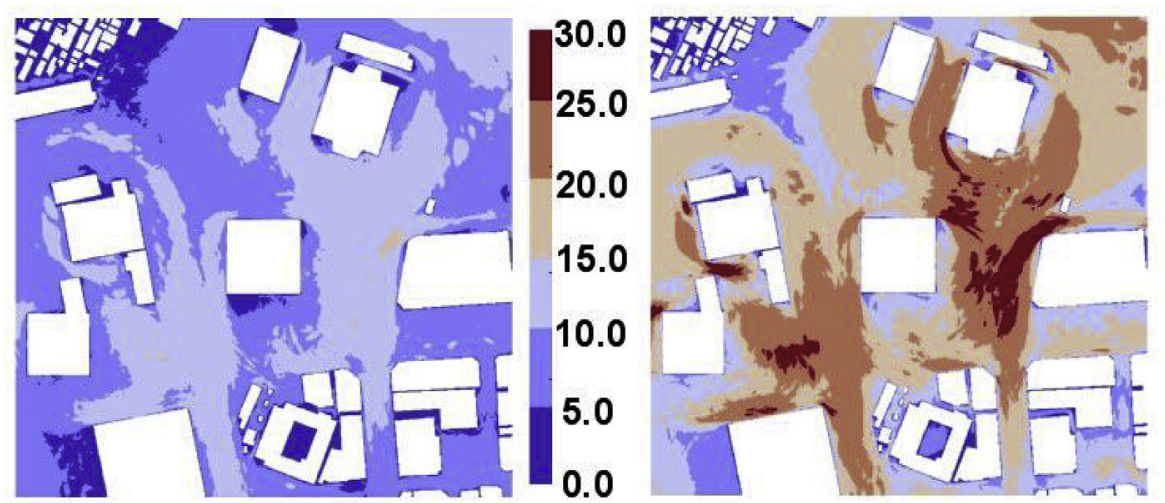

Fig. 11. Visualization of the maximum $3 \mathrm{~s}$ average velocity $(\mathrm{m} / \mathrm{s})$ for $U_{r e f}=5.07 \mathrm{~m} / \mathrm{s}$ (left) and $U_{\text {ref }}=10.14 \mathrm{~m} / \mathrm{s}$ (right).

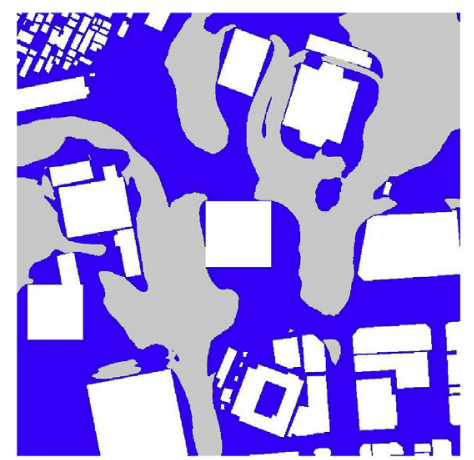

Class A
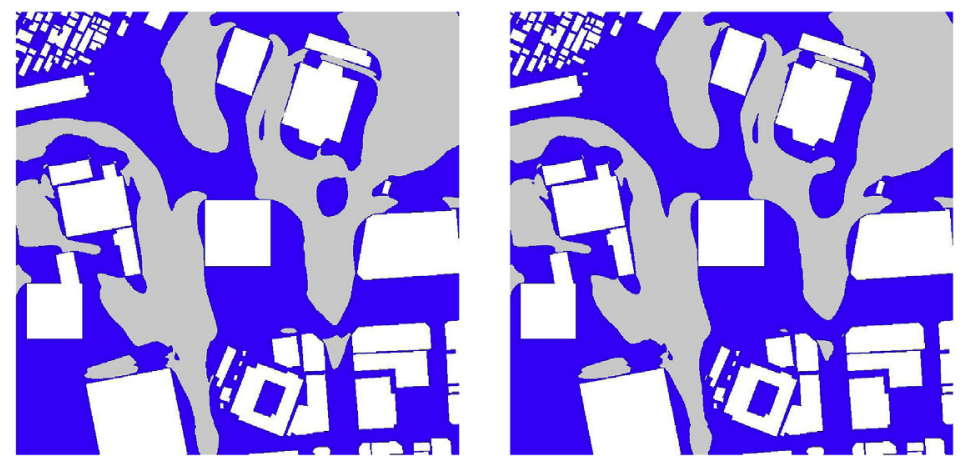

Class B
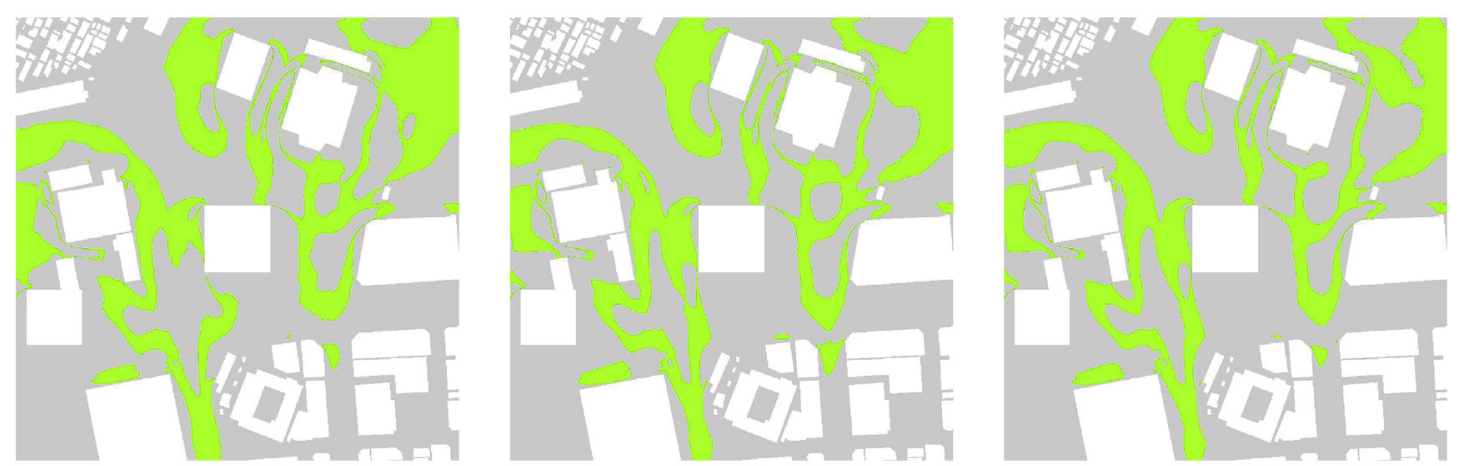

Class C
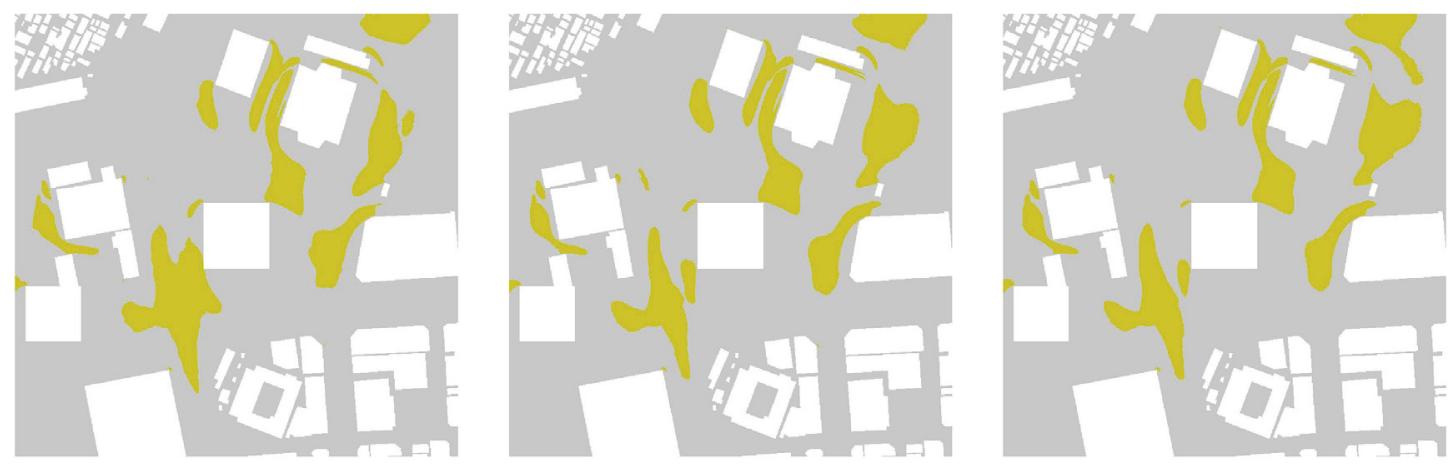

$$
U_{r e f}=1.69 \mathrm{~m} / \mathrm{s}
$$

$$
U_{\text {ref }}=5.07 \mathrm{~m} / \mathrm{s}
$$$$
U_{\text {ref }}=10.14 \mathrm{~m} / \mathrm{s}
$$

Fig. 12. Visualization of the different quality class assessed with Dutch standard criteria using different reference values of the inflow velocity. 


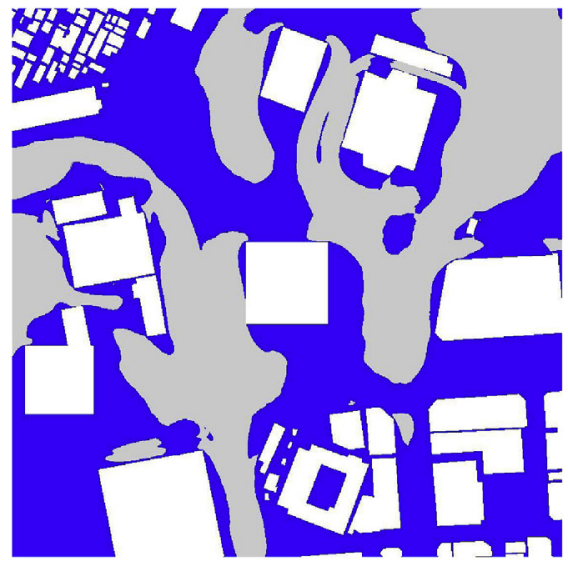

a)

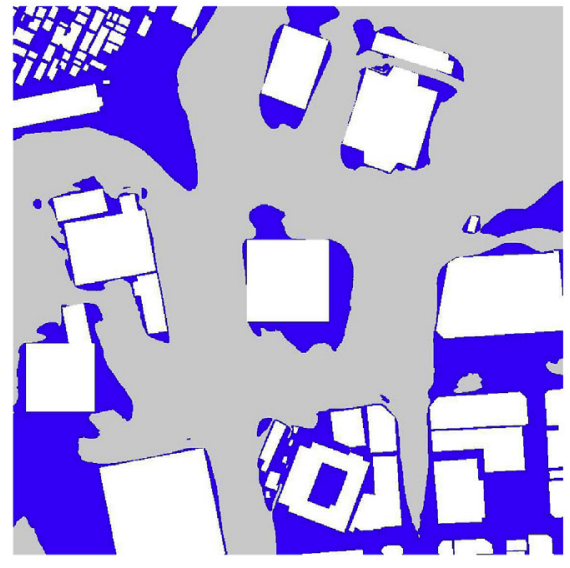

c)

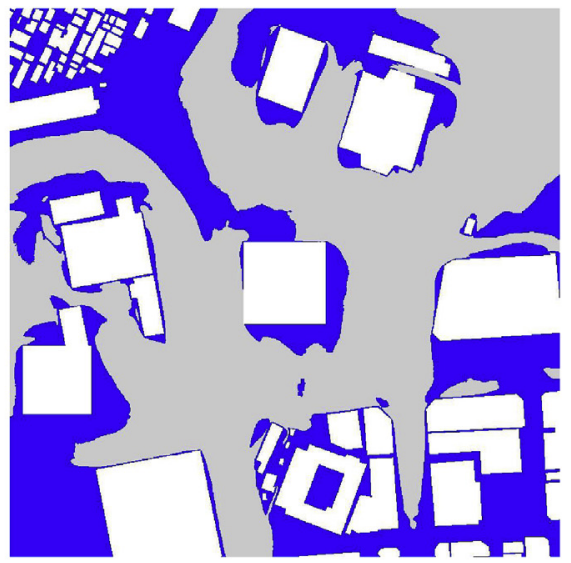

b)

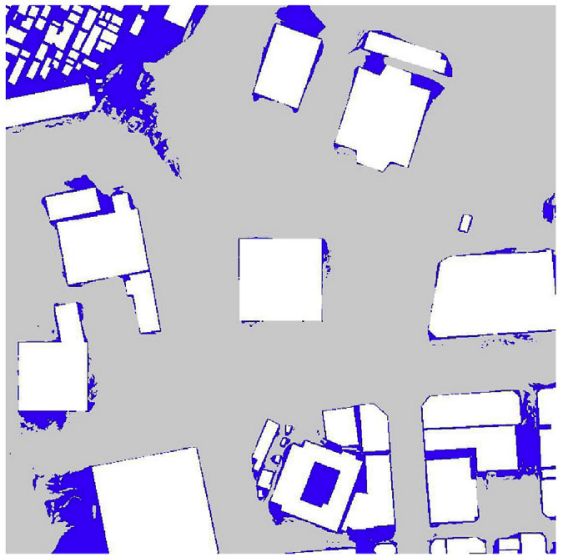

d)

Fig. 13. Visualization of the class A (in blue) with a) NEN8100, b) Melbourne, c) Lawson with $1 \mathrm{~h}$ average velocity and d) Lawson with $3 \mathrm{~s}$ average velocity criteria. (For interpretation of the references to colour in this figure legend, the reader is referred to the Web version of this article.)

install the flow then another one hour time was used to collect samples and compute the flow statistics. The velocity at the different measurements points was normalized by the value of the velocity at the top of the Shinjuku Mitsui building (point D in Fig. 1). We notice that the grid size near the top of that building was the same as the grid size on the floor for all cases to ensure the same level of accuracy for all the measurements points.

We observe from Fig. 3 that the coarse grid do not allow a good recovery of experimental results close to the floor for a majority of measurement points. Grid refinement lead to a clear improvement of the prediction of normalized velocity and the normalized velocities computed from fine grid are in good agreement with both the field and wind tunnel measurements. Grid sensitivity analysis was carried out on the previous measurement points and on other points in Shinjuku area between the coarse and basic grid and between the basic and fine grid. Good agreement between basic and fine grid (Fig. 4) is observed mainly for normalized velocity higher than 0.35 and basic grid could be a good tradeoff between accuracy and computational cost. However in the next part of this work we will address pedestrian wind comfort at a height of $2 \mathrm{~m}$ from the ground and the fine grid seems to be a better choice for that kind of study to ensure accuracy of the results close to the floor.

\section{Application to pedestrian wind comfort}

\subsection{Computational settings}

The domain of study (Fig. 5) for wind comfort assessment is based on the Shinjuku area previously described. An area of interest of $400 m \times 400 m(x \in[-70,330]$ and $y \in[-130,270])$ was defined and a building of $60 \mathrm{~m} \times 60 \mathrm{~m} \times 200 \mathrm{~m}(x \in[100,160]$ and $y \in[40,100])$ was added in that area. Since 1977 lot of new buildings were built in the Shinjuku area and our added building is quite similar to the the Shinjuku Center Building built in 1979. We notice that another building was added in the geometry $(50 m \times 50 m \times 150 m)$ for another study coupled with this one to reduced the computational cost. The area of interest is a uniform grid with $\Delta x=0.5 \mathrm{~m}$ containing 466,375 points $2 \mathrm{~m}$ far from the floor. The boundary conditions are the same as previously and 3 inflow velocity profiles were used, the velocity profile used in Sec. 3, 3 times and 6 times this profile corresponding to $U_{r e f}^{10 m}=1.69 \mathrm{~m} / \mathrm{s}$, $U_{r e f}^{10 m}=5.07 \mathrm{~m} / \mathrm{s}$ and $U_{r e f}^{10 \mathrm{~m}}=10.14 \mathrm{~m} / \mathrm{s}$. The use of the finest grid is in agreement with Tominaga et al. [14] best practices guidelines as we study pedestrian wind comfort on an area higher than the third grid point from the floor.

\subsection{Wind comfort criteria}

Different kind of criteria can be found in the literature, some of them are based on the direct effect of wind on people activities [12,60] and are related to threshold values for the local effective velocity $U_{e}$ from which the realization of these activities become more difficult as summarized in Table 3.

Others criteria are based on two different parameters, namely the definition of the local effective velocity $U_{e}$ as previously, along with the 


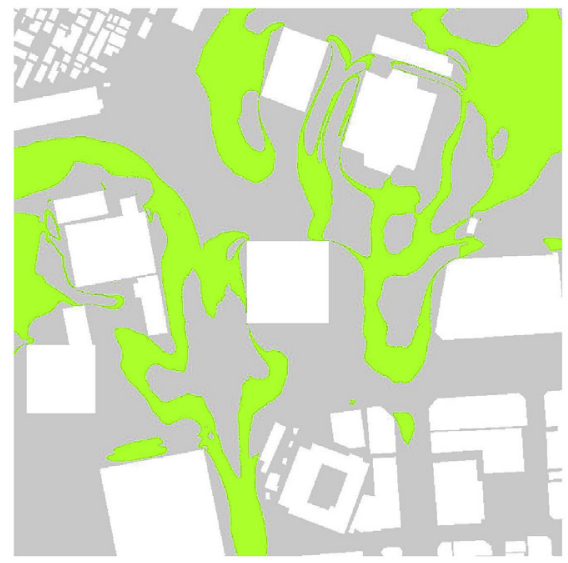

a)

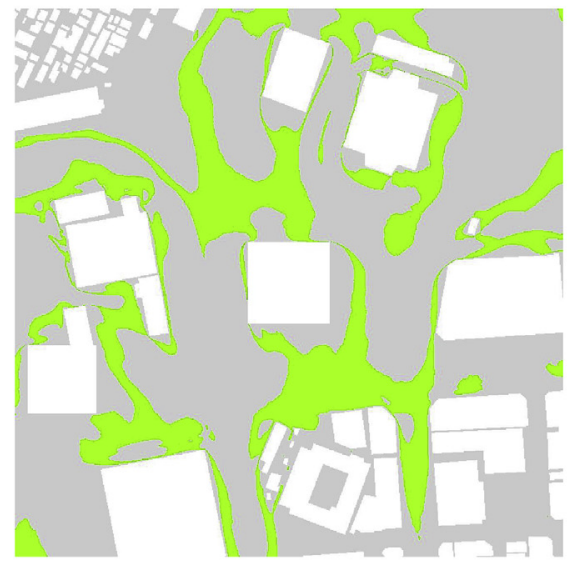

c)

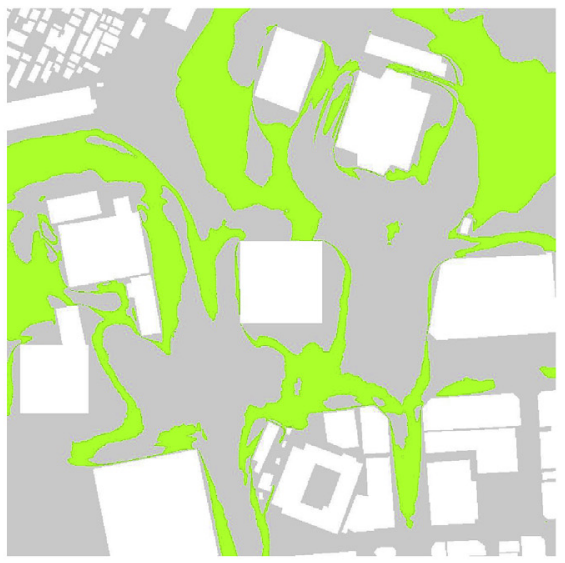

b)

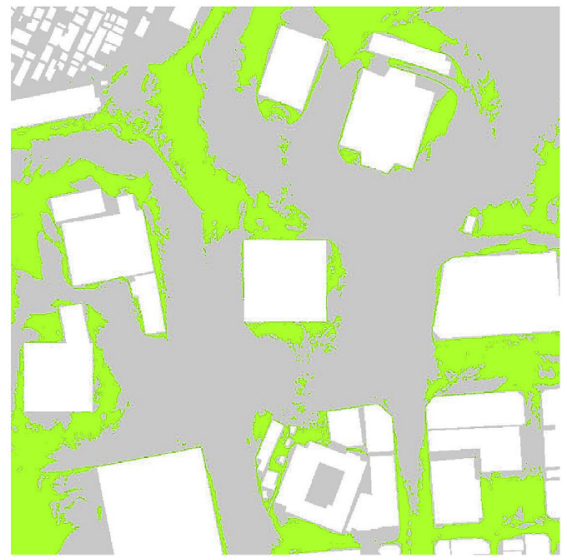

d)

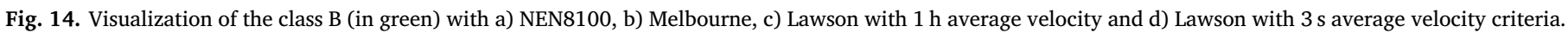
(For interpretation of the references to colour in this figure legend, the reader is referred to the Web version of this article.)

estimation of the probability $P$ that this local effective velocity exceed a threshold value $U_{T H R}$. This probability function is given by Eq. (11) $[20,61]$.

$P_{\theta}\left(U(x)>U_{T H R}\right)=100 \cdot A(\theta) \exp \left[-\left(\frac{U_{T H R}}{G_{\theta}^{x} c(\theta)}\right)^{k(\theta)}\right]$

where $A(\theta), c(\theta)$ and $k(\theta)$ are the Weibull parameters of the direction $\theta$. Sanz-Andres and Cuerva [61] define the amplification factor $G_{\theta}^{x}$ at the point $x$ influenced by a building by the ratio between the velocity $U(x)$ at the point $x$ and the velocity at the reference height of the meteorological station $U_{\text {ref }}$.

$G_{\theta}^{x}=\frac{U(x)}{U_{r e f}}$

The definition of the effective velocity depends on the authors. The relation $U_{e}=\bar{U}+\alpha \sigma_{U}$ is often used with different values of the parameter $\alpha$ : Melbourne [11] used a value $\alpha=3.5$, He and Song [35] used $\alpha=3$ and averages are computed over $10 \mathrm{~min}$ whereas Murakami and Deguchi [60] use $\alpha=0$ with average values computed on $3 \mathrm{~s}$.

Lawson [46] and Isyumov and Davenport [8] define the effective velocity following the Beaufort scale which permit to adapt the method to the average period of the velocity. In the next part of this paper we will consider three different wind comfort criteria, Lawson [46] criteria using velocity average over $3 \mathrm{~s}$ and $1 \mathrm{~h}$, Melbourne [11] using the average velocity and the standard deviation of the velocity and the Dutch standard [45] criteria using the mean velocity. The different pedestrian comfort criteria are summarized in Table 4 and classified following the Dutch standard [45] quality class. Class A means that pedestrian comfort is good for long sitting, class B means that the comfort is good for short exposure and class $\mathrm{C}$ means that the pedestrian comfort is good enough for walking. It is worth noting here that Melbourne [11], Isyumov and Davenport [8] and Lawson [46] defined quality classes with different comments and sometimes other kind of activities than the Dutch standard [45] used here but the main ideas they use to create their classification are the same. In the author opinion all the different criteria presented in Table 3 and Table 4 are complementary, considering that the effect of wind is different following peoples. Children, adults or elderly peoples do not have the same definition of wind comfort so it seems important to use different criteria to assess pedestrian wind comfort in urban areas.

\subsection{Wind comfort assessment}

The computations were performed during $1 \mathrm{~h}$ of physical time to get a physically established unsteady turbulent flow and an additional $1 \mathrm{~h}$ of physical time is computed to collect samples needed to evaluate the various statistical quantities required for that study. During that time the hourly averaged velocity $\bar{U}$, the standard deviation of the velocity $\sigma_{U}$ and the 1200 samples of $3 \mathrm{~s}$ averaged velocities were stored at every grid point of the area, then the local maximum value of the $3 \mathrm{~s}$ average velocity $\overline{U_{\max }^{3 s}}$ was extracted at each point. Fig. 7 and 8 display the time history of the velocity fluctuations for $1 \mathrm{~h}$ of physical time at two locations, one at the east side and one at the west side of the central 


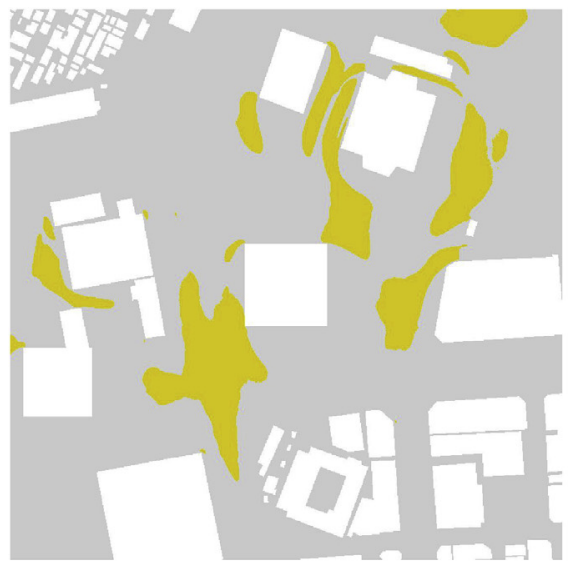

a)

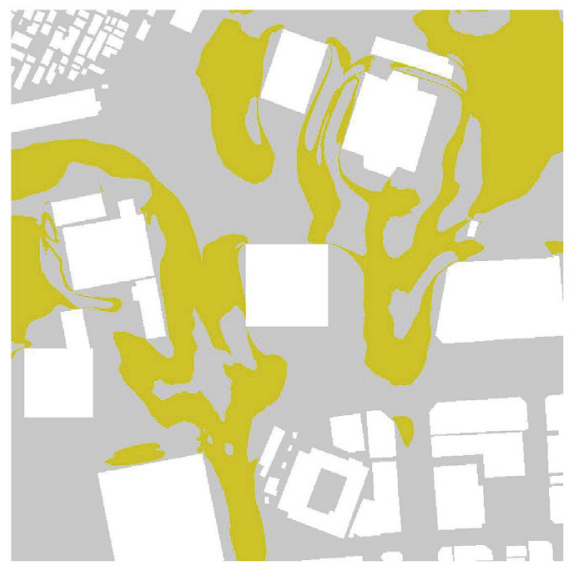

c)

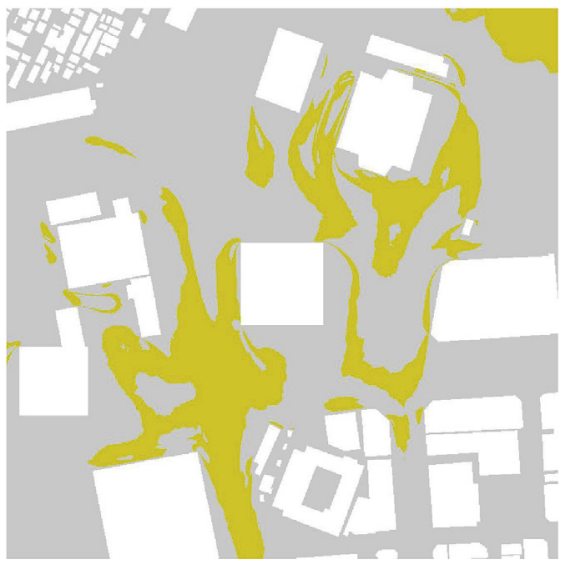

b)

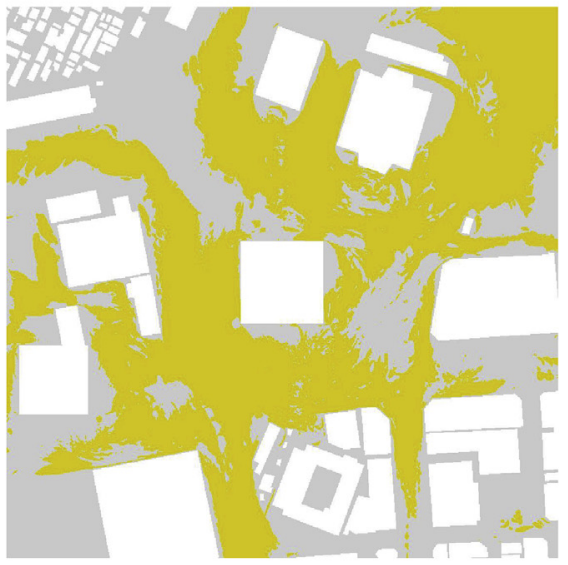

d)

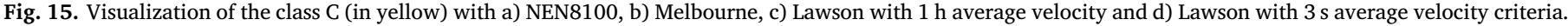
(For interpretation of the references to colour in this figure legend, the reader is referred to the Web version of this article.)

building (Fig. 6). These two locations were chosen because they are located in areas with similar average velocity level $(\bar{U}=2.65 \mathrm{~m} / \mathrm{s}$ for west point and $\bar{U}=2.54 \mathrm{~m} / \mathrm{s}$ at east point) but with very different values for maximal velocity and standard deviation of the velocity (Fig. 10). This means that different physical behaviors are observed on these two locations, mainly on the amplitudes of the velocity fluctuations which are more important on the east point (Fig. 8) than on the west point (Fig. 7).

It is also observed that the sampling time is long enough to get statistically converged quantities, since it is much larger than the observed energetic low frequencies. Fig. 9 shows the velocity histograms for these two points by step of $0.1 \mathrm{~m} / \mathrm{s}$ and the associated Gaussian distributions. In both cases, the main range is located around $2.7 \mathrm{~m} / \mathrm{s}$ (between 2.7 and 2.8 for west point and between 2.6 and 2.7 for east point) but the velocity distributions exhibit some significant differences, which indicate that the flow physics is not the same at the two locations. At the east point, which is in the wake of a tall building, one can observe that the histogram is flatter than at the west point, due to the strong coherent vortical events advected in the wake of the upstream building. Therefore, the flatness of the velocity pdf (probability density function) is not the same at the two test points, for the west point the kurtosis excess $\left(k=\overline{(U-\bar{U})^{4} / \sigma_{U}^{4}}-3\right)$ is negative ( $k=-0.326)$ and positive for the east point $(k=0.123)$. It is also observed that the two histograms are not symmetric with respect to their peak considering that the skewness $\left(s=\overline{(U-\bar{U})^{3} / \sigma_{U}^{3}}\right)$ is negative at these two locations $(s=-0.179$ for west point and $s=-0.125$ for east point). Another important observation is that the velocity pdf is not Gaussian at the two locations since the skewness and kurtosis excess of Gaussian pdf are equal to 0 , showing that simplified wind models based on a Gaussian velocity model may lead to unsatisfactory results.

Pedestrian wind comfort is linked to wind velocity magnitude but also to spatial and temporal velocity fluctuations. Wind speed variability is illustrated in Fig. 10 which displays the 1-hour averaged velocity field, an example of 3-seconds averaged velocity field and the 1hour standard deviation of velocity at $2 \mathrm{~m}$ from the ground. A high spatial variability is observed on the three maps, as expected in dense urban areas in which many building wakes interact and/or impinge on other buildings and that channeling phenomenon is involved between close buildings. As expected, the 3-second averaging yields a less smooth field than the 1-hour averaging, with much wider high-velocity domains. The east test point is observed to be located in a high standard deviation/variability region (as large as $30 \%$ of the mean velocity) influenced by the wakes of three buildings and a strong channeling mechanism. Such a region can therefore be considered as not comfortable for pedestrians due to high velocity fluctuations following Murakami and Deguchi [60] or Hunt et al. [12].

Murakami and Deguchi [60] have shown that 3-seconds averaged velocity higher than $10 \mathrm{~m} / \mathrm{s}$ can lead to serious effects on pedestrians or very serious effects when it exceeds $15 \mathrm{~m} / \mathrm{s}$. From Fig. 10 we can see that such velocity levels do not occur in the simulation with $U_{\text {ref }}=1.69 \mathrm{~m} / \mathrm{s}$ but Fig. 11 shows that increasing the inflow velocity can lead to exceed these threshold velocities. From these results we can say that depending on the inflow velocity it can be very difficult to walk on this area 


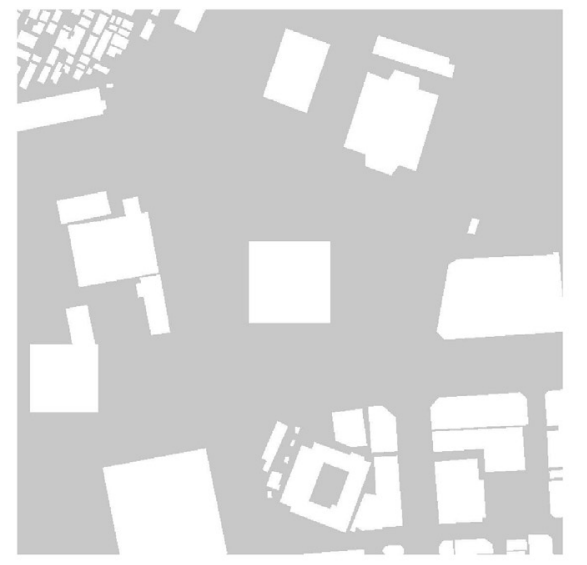

a)

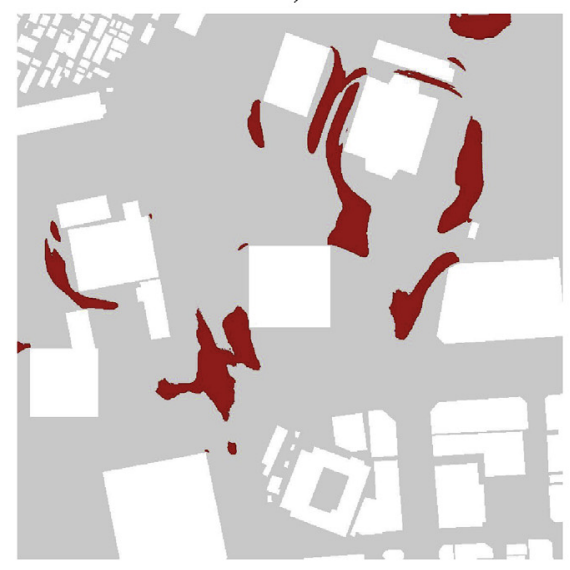

c)

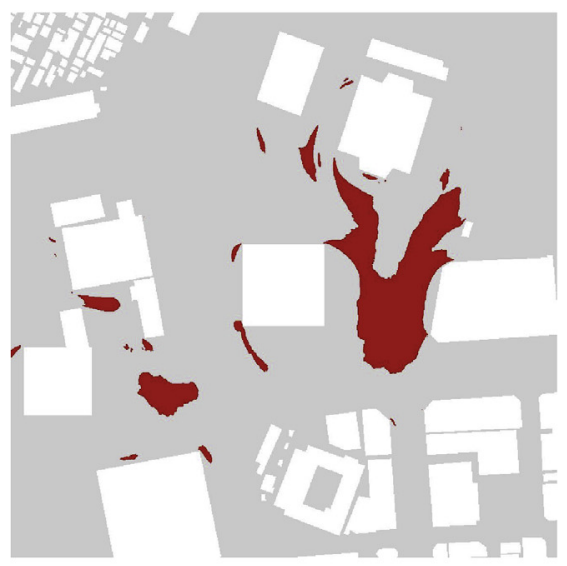

b)

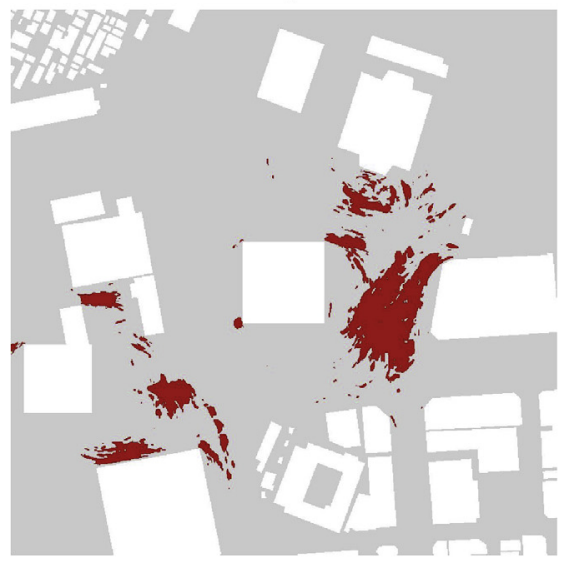

d)

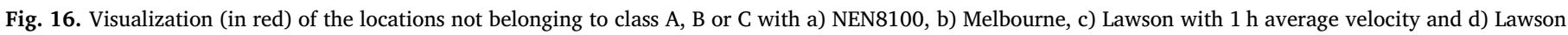
with $3 \mathrm{~s}$ average velocity criteria. (For interpretation of the references to colour in this figure legend, the reader is referred to the Web version of this article.)

Table 5

Fraction (in \%) of points of the Shinjuku area belonging to the different quality class according to several criteria and overlap between them.

\begin{tabular}{lllll}
\hline Criteria & Zone A & Zone B & Zone C & Other zone \\
\hline NEN8100 [45] & $57.5 \%$ & $29 \%$ & $13.5 \%$ & $0 \%$ \\
Melbourne [11] & $41.5 \%$ & $30.8 \%$ & $20.8 \%$ & $6.9 \%$ \\
Lawson [46] $\left(\overline{U_{1 H}}\right)$ & $34 \%$ & $24.6 \%$ & $33.7 \%$ & $7.7 \%$ \\
Lawson [46] $\left(\overline{U_{3 s}}\right)$ & $13.8 \%$ & $29.7 \%$ & $51.1 \%$ & $5.4 \%$ \\
\hline According to all criteria & $13.6 \%$ & $0.14 \%$ & $2.9 \%$ & $0 \%$ \\
\hline
\end{tabular}

$\left(U_{\text {ref }}=10.14 \mathrm{~m} / \mathrm{s}\right)$ or on the contrary very easy $\left(U_{\text {ref }}=1.69 \mathrm{~m} / \mathrm{s}\right)$ that's why it seems interesting to resort to criteria using meteorological data and probability functions in order to be less sensitive to inflow conditions.

Wind comfort assessment based on the Dutch standard [45] for the North wind case was done using simulation data obtained with the 3 reference values for the inflow velocity $\left(U_{r e f}=1.69 \mathrm{~m} / \mathrm{s}, 5.07 \mathrm{~m} / \mathrm{s}\right.$ and $10.14 \mathrm{~m} / \mathrm{s}$ ). The results are shown in Fig. 12. It is seen that increasing the inflow velocity do not change significantly the wind comfort results in that velocity range since class $\mathrm{A}, \mathrm{B}$ and $\mathrm{C}$ locations are almost the same and that $P\left(U>U_{T H R}\right)$ never exceeds $10 \%$ for those 3 cases. It seems that the different criteria as defined in Table 4 are more adapted to general wind comfort assessment than the previous one. All the next applications were made with the velocity results obtained for $U_{\text {ref }}=1.69 \mathrm{~m} / \mathrm{s}$.

The Dutch standard criteria [45] differs from the others ones [11]
[46] since it is based on the probability of exceedance of the threshold velocity of $5 \mathrm{~m} / \mathrm{s}$ whereas the others criteria define several velocities with the same maximal probability exceedance to define different pedestrian wind comfort quality class. Some of the classes defined in Table 4 are illustrated in Figs. 13-15 following the Dutch standard [45], Melbourne [11] and Lawson [46] criteria. As expected Fig. 13 shows that Lawson criterion computed with $\overline{U_{1 H}}$ is more restrictive for long sitting class than the Dutch standard since the threshold velocity and the maximum probability of exceedance are lower.

This figure also shows that building wakes are mostly considered as acceptable for long sitting exposure following the Dutch standard [45] because of their low average velocity whereas they are not following Melbourne criteria [11] because of the important unsteady effects. It seems from Figs. 13-15 that lowering the averaging period on Lawson criterion defined with the Beaufort scale makes it more restrictive: class A area is reduced with computation from $\overline{U_{3 s}}$ and class $\mathrm{C}$ area is increased with $\overline{U_{3 s}}$-based criterion. This comes from the definition of the effective velocity: using $1 \mathrm{~h}$ averaged velocity we account for steady effects of the wind probably more important for long exposure whereas using 3-seconds averaged velocity we take into account wind gust which can affect walking peoples. Fig. 15d) should not be analyzed in the same way since the main part of the study area is not suitable for standing but it shows that wind gust can affect the main part of this area and that pedestrian balance could be momentarily affected. From those figures (13)-(15) Melbourne criteria taking account the local mean flow and the local turbulent intensity seems more restrictive than the Dutch standard, Ohba et al. [2] while comparing several criteria concluded his 


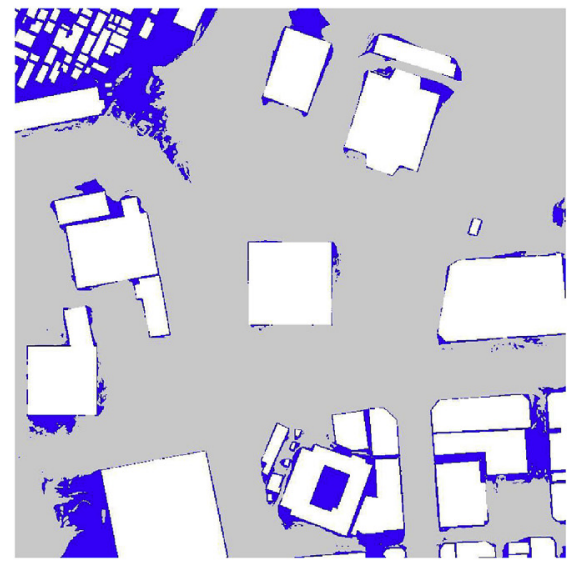

a)

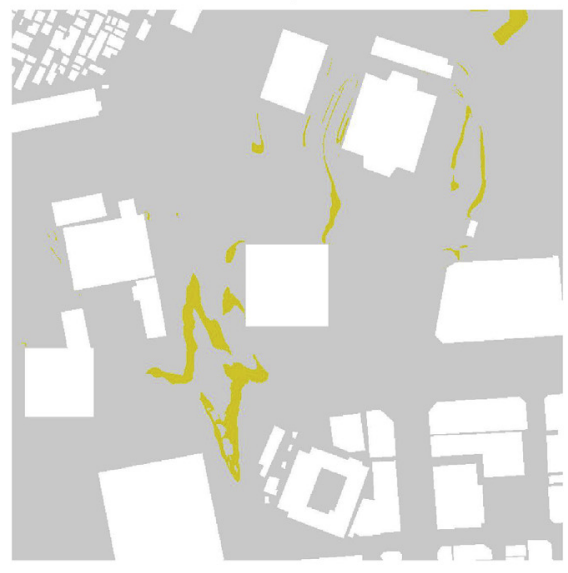

c)

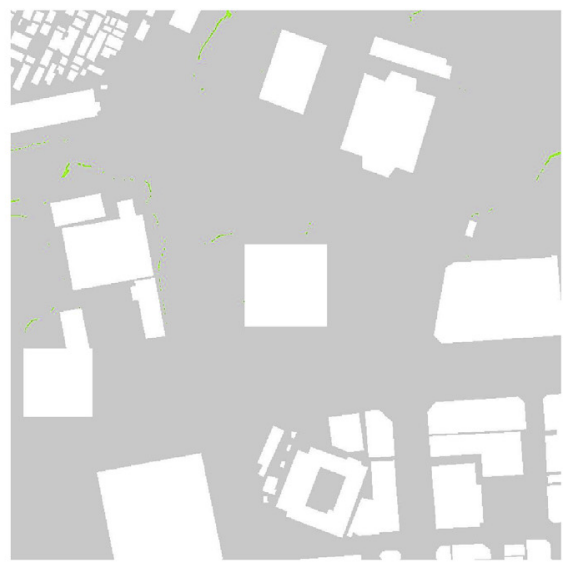

b)

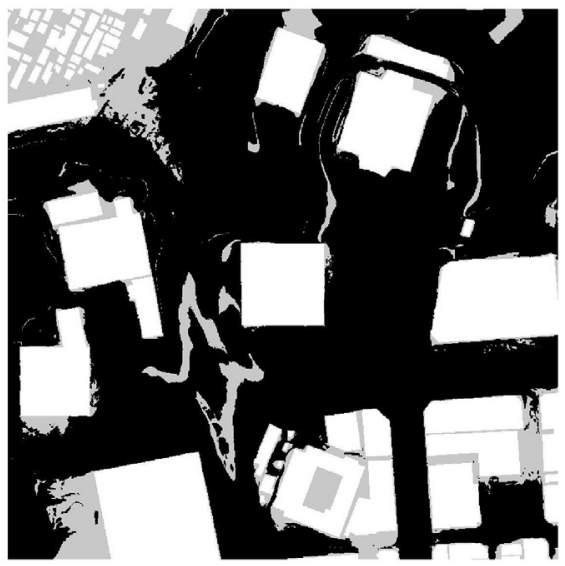

d)

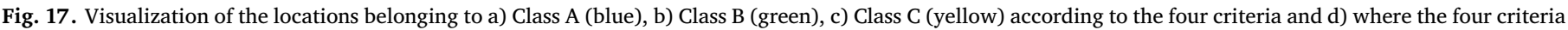
do not agree (black). (For interpretation of the references to colour in this figure legend, the reader is referred to the Web version of this article.)

assessment results in a severe evaluation of pedestrian comfort compared to Murakami et al. [60] and Isyumov and Davenport [8] criteria.

Fig. 16 shows locations that do not belong to classes A, B or C, i.e. locations where pedestrian comfort is not acceptable for sitting or normal walking according to the different criteria. It seems that such locations are almost not present in the test domain according to Dutch standard whereas few locations, mostly in the wake of the top right building, are found following the other criteria. These locations are subjected to more important unsteady effects (see Fig. 3) than the others so it's not surprising to have few differences in the results of the different criteria depending on the definition of their effective velocity or the value of the maximum probability of the threshold velocity. From these results it seems that the use of different criteria for wind comfort assessment is interesting considering they are taking into account different parameter such as mean velocity, turbulent intensity or wind gust. These parameters are important parameters to define pedestrian wind comfort criteria.

The differences between the existing criteria is further emphasized looking at Table 5, which displays the percentage $R=100 N_{i} / N$ (with $N_{i}$ the number of grid points in class i and $N$ the total number of grid points in the area) of the total test area for each class obtained with the various criteria. The last line deals with the overlap of the point of the same class obtained with the four criteria. A striking conclusion is that the overlap is almost null, indicating that criteria are not equivalent at all and that they lead to very different conclusions in practical cases (see Fig. 17). The duration of the time-averaging period is also seen to be of crucial importance when using Lawson's criterion. As a matter of fact, a long averaging time results in a strong smoothing of the extrema of the instantaneous signal, yielding the prediction of large areas in zone A (about $1 / 3$ of the total area in the present test case). On the opposite, considering a short time averaging does not eliminate the strong wind gusts, yielding a much more restricted comfort map.

\subsection{Wind comfort criteria combinations}

Since the different criteria proposed in the literature lead to different pedestrian comfort map as shown in Fig. 17, the use of a new criterion combining the previously defined criteria is necessary. In this study we proposed 4 new criteria:

- Criterion 1: for every grid point the less restrictive criterion assess is kept,

- Criterion 2: for every grid point the most restrictive criterion assess is kept,

- Criterion 3: for every grid point the most often predicted criterion is used, in case of a tie between two criteria the less restrictive is kept,

- Criterion 4: for every grid point the most often predicted criterion is used, in case of a tie between two criteria the more restrictive is kept.

Fig. 18 shows the comfort maps obtained with these new criteria. The criterion 1 using the less restrictive assessment lead to comfort map quite similar to the one obtain with the Dutch standard criteria. The criterion 2 gives results very close to Lawson criterion that was more 


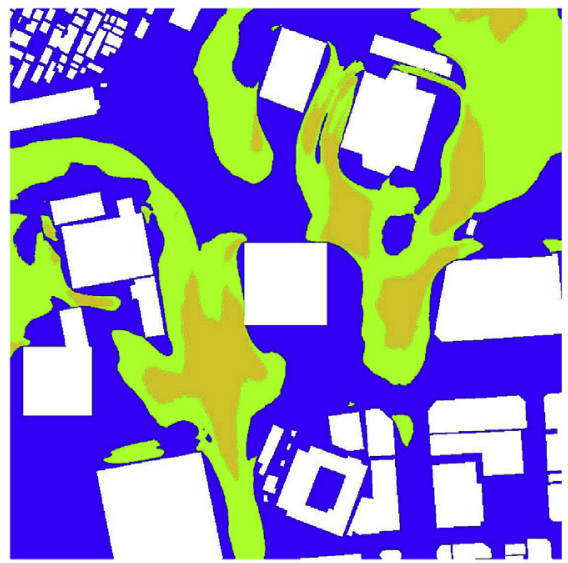

a)

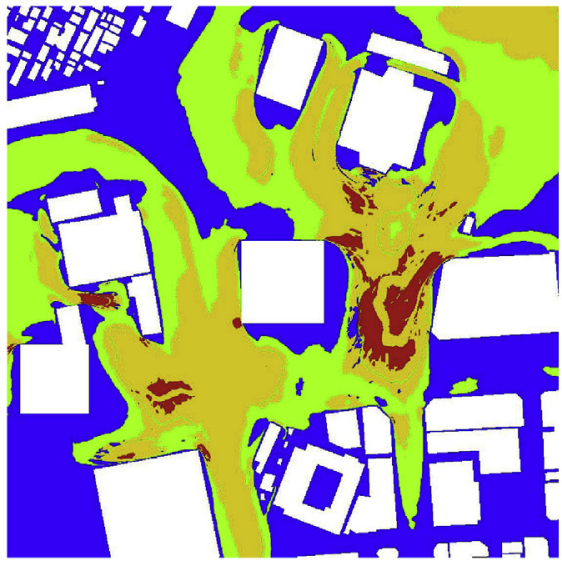

c)

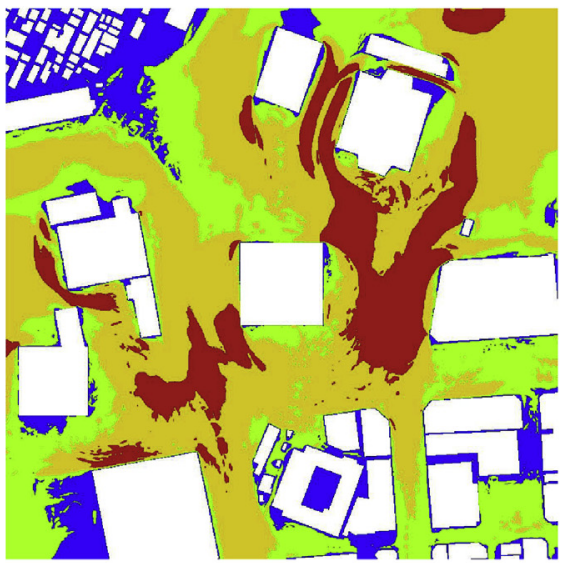

b)

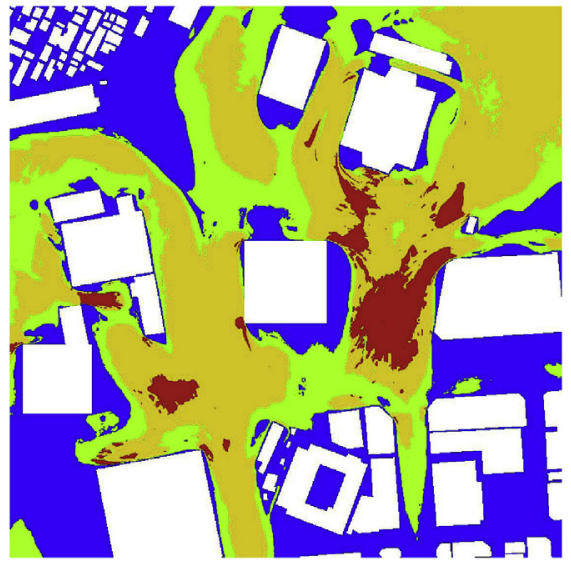

d)

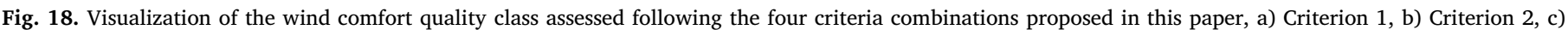

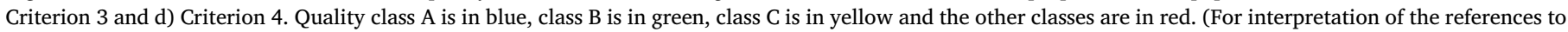
colour in this figure legend, the reader is referred to the Web version of this article.)

restrictive than the other ones. These two criteria are probably not the most representative since they are based on the extreme values assessed by the standard criteria. On the opposite the comfort map obtained using the proposed criteria 3 and 4 based on the most predicted class for each point seems to be a good compromise for wind comfort assessment. The main differences between these both criteria appears between class $\mathrm{B}$ and $\mathrm{C}$ around the two north buildings but the global aspect of the comfort map is very similar for these two criteria. In authors opinion, the use of CFD velocity fields combined with the proposed criteria 3 or 4 estimated from many different commonly used criteria seems an interesting way for wind comfort assessment since it will lead to more representative comfort map by removing extreme values.

\section{Conclusions}

Several LBM-based LES of urban flow in a realistic full scale case have been carried out, with application to wind comfort. A first observation is that LES provides a deep insight into flow physics and gives access to a huge amount of physically relevant and accurate data that can be used as input for wind comfort criteria. An observation is that wind velocity fluctuations, which originate in the combination of many physical phenomena (wakes, boundary layers, channeling ...) are not Gaussian fluctuations. Using LES unsteady data, it is observed that wind comfort criteria that include wind unsteadiness as an input parameter can lead to conclusions that are very different from those based on mean flow velocity amplitude. This illustrates the fact that unsteady
CFD approaches such as LES or DES should be privileged for wind comfort studies. Another observation is that the various existing criteria lead to significantly different results on the same case which complicates their practical use. In this study several methods have been proposed to combine the different criteria available in the literature. In order to get a robust conclusion in practical applications the use of a large amount of these classical wind comfort criteria is recommended to keep the more often predicted criteria.

\section{Acknowledgments}

This work was supported by the French project CLIMB, with the financial support of BPIFrance (Project No. P3543-24000), in the framework of the program "Investissement d'Avenir: Calcul Intensif et Simulation Numérique". This work was performed using HPC resources from GENCI-TGCC/CINES (Grant 2017-A0012A07679).

\section{References}

[1] M.A. Ratcliff, J.A. Peterka, Comparison of pedestrian wind acceptability criteria, J. Wind Eng. Ind. Aerod. 36 (Part 2) (1990) 791-800 https://doi.org/10.1016/0167. 6105(90)90076-O http://www.sciencedirect.com/science/article/pii/ 0167610590900760 .

[2] M. Ohba, N. Kobayashi, S. Murakami, Study on the assessment of environmental wind conditions at ground level in a built-up area - based on long-term measurements using portable 3-cup anemometers-, J. Wind Eng. Ind. Aerod. 28 (1) (1988) 129-138 https://doi.org/10.1016/0167-6105(88)90109-2 http://www.

sciencedirect.com/science/article/pii/0167610588901092. 
[3] M. Bottema, A method for optimisation of wind discomfort criteria, Build. Environ. 35 (1) (2000) 1-18 https://doi.org/10.1016/S0360-1323(98)00065-1 http://www. sciencedirect.com/science/article/pii/S0360132398000651.

[4] H.H. Koss, On differences and similarities of applied wind comfort criteria, J. Wind Eng. Ind. Aerod. 94 (2006) 781-797 Urban Civil Engineering (UCE), Impact of wind and storms on city life and built environment https://doi.org/10.1016/j.jweia. 2006.06.005 http://www.sciencedirect.com/science/article/pii/ S0167610506000870.

[5] A. Davenport, An approach to human comfort criteria for environmental wind conditions, Colloqium on Building Climatology, 1972.

[6] J. Gandemer, Wind environment around buildings: aerodynamic concept, Fourth International Colloqium on Wind Effects on Buildings and Structures, Cambridge University Press, Heathrow, UK, 1975.

[7] J. Gandemer, Aerodynamic studies of built-up areas made by C.S.T.B. at Nantes, France, J. Wind Eng. Ind. Aerod. 3 (2) (1978) 227-240 the wind content of the built environment https://doi.org/10.1016/0167-6105(78)90012-0 http://www. sciencedirect.com/science/article/pii/0167610578900120.

[8] N. Isyumov, A. Davenport, The ground level wind environment in built-up areas, Fourth International Colloqium on Wind Effects on Buildings and Structures, Cambridge University Press, Heathrow, UK, 1975, pp. 403-422.

[9] N. Isyumov, A. Davenport, Evaluation of the effects of tall buildings on pedestrian level wind environment, ASCE Annual Convention.

[10] T. Lawson, A. Penwarden, The effects of wind on people in the vicinity of buildings, Fourth International Colloqium on Wind Effects on Buildings and Structures, Cambridge University Press, Heathrow, UK, 1975, pp. 605-622.

[11] W. Melbourne, Criteria for environmental wind conditions, J. Ind. Aerod. 3 (1978) 241-249.

[12] J.C.R. Hunt, E.C. Poulton, J.C. Mumford, The effects of wind on people; new criteria based on wind tunnel experiments, Build. Environ. 11 (1) (1976) 15-28 https://doi. org/10.1016/0360-1323(76)90015-9 http://www.sciencedirect.com/science/ article/pii/0360132376900159.

[13] J. Franke, A. Hellsten, H. Schlunzen, B. Carissimo, Best practice guideline for the CFD simulation of flows in the urban environment, COST 732: Quality Assurance and Improvement of Microscale Meteorological Models.

[14] Y. Tominaga, A. Mochida, R. Yoshie, H. Kataoka, T. Nozu, M. Yoshikawa, T. Shirasawa, AIJ guidelines for practical applications of CFD to pedestrian wind environment around buildings, J. Wind Eng. Ind. Aerod. 96 (10) (2008) 1749-1761 4th International Symposium on Computational Wind Engineering (CWE2006) https://doi.org/10.1016/j.jweia.2008.02.058 http://www.sciencedirect.com/ science/article/pii/S0167610508000445.

[15] B. Blocken, Computational Fluid Dynamics for urban physics: importance, scales, possibilities, limitations and ten tips and tricks towards accurate and reliable simulations, Build. Environ. 91 (2015) 219-245 fifty Year Anniversary for Building and Environment https://doi.org/10.1016/j.buildenv.2015.02.015 http://www. sciencedirect.com/science/article/pii/S0360132315000724.

[16] B. Blocken, J. Carmeliet, T. Stathopoulos, CFD evaluation of wind speed conditions in passages between parallel buildingseffect of wall-function roughness modifications for the atmospheric boundary layer flow, J. Wind Eng. Ind. Aerod. 95 (9) (2007) 941-962 https://doi.org/10.1016/j.jweia.2007.01.013 http://www. sciencedirect.com/science/article/pii/S0167610507000268.

[17] Y. Du, C.M. Mak, J. Liu, Q. Xia, J. Niu, K. Kwok, Effects of lift-up design on pedestrian level wind comfort in different building configurations under three wind directions, Build. Environ. 117 (2017) 84-99 https://doi.org/10.1016/j.buildenv. 2017.03.001 http://www.sciencedirect.com/science/article/pii/ S0360132317300884.

[18] R. Yoshie, A. Mochida, Y. Tominaga, H. Kataoka, K. Harimoto, T. Nozu, T. Shirasawa, Cooperative project for CFD prediction of pedestrian wind environment in the Architectural Institute of Japan, J. Wind Eng. Ind. Aerod. 95 (9) (2007) 1551-1578 https://doi.org/10.1016/j.jweia.2007.02.023 http://www. sciencedirect.com/science/article/pii/S0167610507000645.

[19] J.-J. Kim, J.-J. Baik, A numerical study of the effects of ambient wind direction on flow and dispersion in urban street canyons using the RNG $k-\varepsilon$ turbulence model, Atmos. Environ. 38 (19) (2004) 3039-3048 https://doi.org/10.1016/j.atmosenv. 2004.02.047 http://www.sciencedirect.com/science/article/pii/ S1352231004001773.

[20] B. Blocken, S. Roels, J. Carmeliet, Modification of pedestrian wind comfort in the Silvertop Tower passages by an automatic control system, J. Wind Eng. Ind. Aerod. 92 (10) (2004) 849-873 https://doi.org/10.1016/j.jweia.2004.04.004 http:// www sciencedirect.com/science/article/pii/S0167610504000674.

[21] B. Blocken, J. Persoon, Pedestrian wind comfort around a large football stadium in an urban environment: CFD simulation, validation and application of the new Dutch wind nuisance standard, J. Wind Eng. Ind. Aerod. 97 (5) (2009) 255-270 https://doi.org/10.1016/j.jweia.2009.06.007 http://www.sciencedirect.com/ science/article/pii/S0167610509000518.

[22] B. Blocken, W. Janssen, T. van Hooff, CFD simulation for pedestrian wind comfort and wind safety in urban areas: general decision framework and case study for the Eindhoven university campus, Environ. Model. Software 30 (2012) 15-34 https:// doi.org/10.1016/j.envsoft.2011.11.009 http://www.sciencedirect.com/science/ article/pii/S1364815211002647.

[23] W. Janssen, B. Blocken, T. van Hooff, Pedestrian wind comfort around buildings: comparison of wind comfort criteria based on whole-flow field data for a complex case study, Build. Environ. 59 (2013) 547-562 https://doi.org/10.1016/j.buildenv. 2012.10.012 http://www.sciencedirect.com/science/article/pii/ S0360132312002776.

[24] G. Kang, J.-J. Kim, D.-J. Kim, W. Choi, S.-J. Park, Development of a computational fluid dynamics model with tree drag parameterizations: application to pedestrian wind comfort in an urban area, Build. Environ. 124 (2017) 209-218 https://doi org/10.1016/j.buildenv.2017.08.008 http://www.sciencedirect.com/science/ article/pii/S0360132317303542.

[25] S. Liu, W. Pan, H. Zhang, X. Cheng, Z. Long, Q. Chen, CFD simulations of wind distribution in an urban community with a full-scale geometrical model, Build. Environ. 117 (2017) 11-23 https://doi.org/10.1016/j.buildenv.2017.02.021 http://www.sciencedirect.com/science/article/pii/S0360132317300811.

[26] H. Montazeri, B. Blocken, W. Janssen, T. van Hooff, CFD evaluation of new secondskin facade concept for wind comfort on building balconies: case study for the Park Tower in Antwerp, Build. Environ. 68 (2013) 179-192 https://doi.org/10.1016/j. buildenv.2013.07.004 http://www.sciencedirect.com/science/article/pii/ S0360132313001959.

[27] Y. Tominaga, R. Yoshie, A. Mochida, H. Kataoka, K. Harimoto, T. Nozu, Cross comparisons of CFD prediction for wind environment at pedestrian level around buildings. comparison of results for flowfield around building complex in actual urban area, The Sixth Asia-Pacific Conference on Wind Engineering, APCWE-VI, Seoul, Korea, 2005.

[28] T. van Hooff, B. Blocken, Coupled urban wind flow and indoor natural ventilation modelling on a high-resolution grid: a case study for the Amsterdam ArenA stadium, Environ. Model. Software 25 (1) (2010) 51-65 https://doi.org/10.1016/j.envsoft 2009.07.008 http://www.sciencedirect.com/science/article/pii/ S1364815209001790.

[29] C. Zheng, Y. Li, Y. Wu, Pedestrian-level wind environment on outdoor platforms of a thousand-meter-scale megatall building: sub-configuration experiment and wind comfort assessment, Build. Environ. 106 (2016) 313-326 https://doi.org/10.1016/ j.buildenv.2016.07.004 http://www.sciencedirect.com/science/article/pii/ S0360132316302517.

[30] P. Sagaut, S. Deck, M. Terracol, Multiscale and Multiresolution Approaches in Turbulence, Imperial College Press, London, 2006.

[31] J. Liu, J. Niu, C.M. Mak, Q. Xia, Detached eddy simulation of pedestrian-level wind and gust around an elevated building, Build. Environ. 125 (Supplement C) (2017) 168-179 https://doi.org/10.1016/j.buildenv.2017.08.031 http://www. sciencedirect.com/science/article/pii/S0360132317303864.

[32] R.E. Dadioti, S. Rees, Validation of a datached eddy simulation (DES) model in complex urban environment, Athens J. Sci. 3 (2) (2016) 113-136.

[33] P. Sagaut, Large Eddy Simulation for Incompressible Flows: an Introduction, third ed., Springer, Berlin, 2005.

[34] E. Garnier, N. Adams, P. Sagaut, Large-eddy Simulation for Compressible Flows, Springer, Berlin, 2009.

[35] J. He, C.C.S. Song, Evaluation of pedestrian winds in urban area by numerical approach, J. Wind Eng. Ind. Aerod. 81 (1999) 295-309.

[36] Z.-T. Xie, O. Coceal, I.P. Castro, Large-eddy simulation of flows over random urbanlike obstacles, Boundary-Layer Meteorol. 129 (2008) 1-23.

[37] A.A. Razak, A. Hagishima, N. Ikegaya, J. Tanimoto, Analysis of airflow over building arrays for assessment of urban wind environment, Build. Environ. 59 (Supplement C) (2013) 56-65 https://doi.org/10.1016/j.buildenv.2012.08.007 http://www.sciencedirect.com/science/article/pii/S0360132312002090.

[38] R. Shi, G. Cui, Z. Wang, C. Xu, Z. Zhang, Large eddy simulation of wind field and plume dispersion in building array, Atmos. Environ. 42 (6) (2008) 1083-1097 https://doi.org/10.1016/j.atmosenv.2007.10.071 http://www.sciencedirect.com/ science/article/pii/S1352231007009910.

[39] M.O. Letzel, M. Krane, S. Raasch, High resolution urban large-eddy simulation studies from street canyon to neighbourhood scale, Atmos. Environ. 42 (2008) 8770-8784.

[40] P. Gousseau, B. Blocken, T. Stathopoulos, G. van Heijst, Near-field pollutant dispersion in an actual urban area: analysis of the mass transport mechanism by high resolution Large Eddy Simulations, Comput. Fluids 114 (2015) 151-162 https:// doi.org/10.1016/j.compfluid.2015.02.018 http://www.sciencedirect.com/science/ article/pii/S0045793015000614.

[41] A. Elshaer, H. Aboshosha, G. Bitsuamlak, A.E. Damatty, A. Dagnew, LES evaluation of wind-induced responses for an isolated and a surrounded tall building, Eng. Struct. 115 (2016) 179-195 https://doi.org/10.1016/j.engstruct.2016.02.026 http://www.sciencedirect.com/science/article/pii/S0141029616001140.

[42] M.O. Letzel, C. Helmke, E. Ng, X. An, A. Lai, S. Raasch, LES case study on pedestrian level ventilation in two neighbourhoods in Hong Kong, Meteorol. Z. 21 (6) (2012) $575-589$.

[43] K. Adamek, N. Vasan, A. Elshaer, E. English, G. Bitsuamlak, Pedestrian level wind assessment through city development: a study of the financial district in Toronto, Sustain. Cities. Soc. 35 (2017) 178-190.

[44] N.H. Ahmad, A. Inagaki, M. Kanda, N. Onodera, T. Aoki, Large-eddy simulation of the gust index in an urban area using the lattice Boltzmann method, BoundaryLayer Meteorol. 163 (2017) 447-467.

[45] NEN, Wind comfort and wind danger in the built environment, NEN8100 (in Dutch) Dutch standard.

[46] T. Lawson, The wind content of the built environment, J. Wind Eng. Ind. Aerod. 3 (2) (1978) 93-105 the wind content of the built environment https://doi.org/10. 1016/0167-6105(78)90002-8 http://www.sciencedirect.com/science/article/pii/ 0167610578900028.

[47] X. Shi, Y. Zhu, J. Duan, R. Shao, J. Wang, Assessment of pedestrian wind environment in urban planning design, Landsc. Urban Plann. 140 (Supplement C) (2015) 17-28 https://doi.org/10.1016/j.landurbplan.2015.03.013 http://www. sciencedirect.com/science/article/pii/S0169204615000754.

[48] M.J. Soligo, P.A. Irwin, C.J. Williams, G.D. Schuyler, A comprehensive assessment of pedestrian comfort including thermal effects, J. Wind Eng. Ind. Aerod. 77-78 (Supplement C) (1998) 753-766 https://doi.org/10.1016/S0167-6105(98)00189-5 http://www.sciencedirect.com/science/article/pii/S0167610598001895. 
[49] CS, ProLB (2018). URL http://www.prolb-cfd.com/.

[50] S. Succi, The Lattice Boltzmann Equation for Fluid Dynamics and beyond, Oxford University Press, Oxford, 2001.

[51] Z. Guo, C. Shu, The Lattice Boltzmann Method and its Applications in Engineering, World Scientific, 2013

[52] T. Kruüger, H. Kusumaatmaja, A. Kuzmin, O. Shardt, G. Silva, E. Viggen, The Lattice Boltzmann Method. Principles and Practice, Springer, 2017.

[53] X. He, L.-S. Luo, Theory of the lattice Boltzmann method: from the Boltzmann equation to the lattice Boltzmann equation, Phys. Rev. E 56 (6) (1997) 6811-6817.

[54] X. Shan, X.-F. Yuan, H. Chen, Kinetic theory representation of hydrodynamics: a way beyond the Navier-Stokes equation, J. Fluid Mech. 550 (2006) 413-441.

[55] D. Yu, R. Mei, L.-S. Luo, W. Shyy, Viscous flow computations with the method of lattice Boltzmann equation, Prog. Aero. Sci. 39 (5) (2003) 329-367.

[56] D. d' Humières, I. Ginzburg, M. Krafczyk, P. Lallemand, L.-S. Luo, Multiple-relaxation-time lattice Boltzmann models in three dimensions, Phil. Trans. Roy. Soc. Lond. 360 (2002) 437-451.

[57] J. Latt, B. Chopard, Lattice Boltzmann method with regularized pre-collision distribution functions, Math. Comput. Simulat. 72 (2006) 165-168.

[58] J. Latt, Hydrodynamic Limit of Lattice Boltzmann Equations, PhD dissertation University of Geneva, Geneva, Switzerland, 2007http://www.unige.ch/ cyberdocuments/theses2007/LattJ/meta.html.

[59] N. Afzal, A. Seena, A. Bushra, Turbulent flow in a machine honed rough pipe for large Reynolds numbers: general roughness scaling laws, J. Hydro-environ. Res. 7 (1) (2013) 81-90 https://doi.org/10.1016/j.jher.2011.08.002 http://www. sciencedirect.com/science/article/pii/S157064431100075X.

[60] S. Murakami, K. Deguchi, New criteria for wind effects on pedestrians, J. Wind Eng. Ind. Aerod. 7 (3) (1981) 289-309 https://doi.org/10.1016/0167-6105(81)90055-6 http://www.sciencedirect.com/science/article/pii/0167610581900556.

[61] A. Sanz-Andres, A. Cuerva, Pedestrian wind comfort: feasibility study of criteria homogenisation, J. Wind Eng. Ind. Aerod. 94 (11) (2006) 799-813 Urban Civil Engineering (UCE), Impact of wind and storms on city life and built environment https://doi.org/10.1016/j.jweia.2006.06.004 http://www.sciencedirect.com/ science/article/pii/S0167610506000882. 